\title{
Fast Physics and Slow Physics in the Nonlinear Dansgaard-Oeschger Relaxation Oscillation
}

\author{
Guido VetToretti AND W. Richard Peltier \\ Department of Physics, University of Toronto, Toronto, Ontario, Canada
}

(Manuscript received 17 August 2017, in final form 11 December 2017)

\begin{abstract}
The Dansgaard-Oeschger (D-O) relaxation oscillation that governed glacial climate variability during marine isotope stage 3 has been accurately simulated using a high-resolution coupled climate model. Here the authors present additional detailed analyses of both the slow physics transition between warm and cold states and the fast physics transition between cold and warm states of the D-O cycle. First, the authors demonstrate that the mechanisms active during the slow transition from interstadial to stadial conditions involves the continuous flux of thick and old sea ice from the Arctic basin into the North Atlantic subpolar gyre region along the East Greenland Current. During this slow physical process, the freshwater input from sea ice melting as it moves over the surface of the warm ocean restratifies the high-latitude North Atlantic and leads to a significant reduction in the rate of North Atlantic Deep Water formation. A detailed freshwater budget and hydrography analysis is also presented to demonstrate that the D-O cycle is a low-latitude-high-latitude salt oscillator as the authors have previously argued. Second, the authors provide a more detailed analysis than previously of the fast-time-scale processes that govern the extremely rapid transition from cold stadial conditions back to the warm interstadial state. These are associated with the onset of a sub-sea ice thermohaline convective instability, which opens a massive polynya to the north of the southern boundary of the extensive North Atlantic sea ice lid that is characteristic of stadial conditions. This instability is enabled by the continuous increase of salinity above the sub-sea ice pycnocline, which eliminates the vertical salinity gradient that prevents convective destabilization of the water column under full stadial conditions. This reduction in the vertical salinity gradient beneath the sea ice lid results from the continuing northward salt transport by the North Atlantic gyre circulation once the expansion of the stadial sea ice lid has ceased. The onset of instability occurs in the Irminger basin to the south of Denmark Strait, and the authors discuss the reason for this localization of instability onset.
\end{abstract}

\section{Introduction}

One of the most enigmatic and energetically debated problems in paleoclimate research continues to involve the development of a consensus theoretical understanding of the mechanisms that underlie the millennium time-scale oscillations of glacial North Atlantic climate (e.g., Andersen et al. 2004). First discovered through the work of Willi Dansgaard and Hans Oeschger (Dansgaard et al. 1993), Dansgaard-Oeschger (D-O) oscillations are one of the defining features of Late Pleistocene glacial climate variability. An initial

Supplemental information related to this paper is available at the Journals Online website: https://doi.org/10.1175/ JCLI-D-0559.s1.

Corresponding author: Guido Vettoretti, g.vettoretti@utoronto.ca explanation of the D-O oscillation phenomenon suggested by Broecker et al. (1985) was that it might involve the partial growth and decay of grounded continental ice sheets that surrounded the glacial North Atlantic basin. Interstadial conditions were envisioned to warm the Northern Hemisphere, increasing North Atlantic freshening through increased meltwater from melting land ice sheets, along with increased precipitation in the subtropical North Atlantic from a northward-shifted intertropical convergence zone (ITCZ). This was suggested to drive the system back into a stadial state with a resultant net positive surface buoyancy flux being applied over regions of North Atlantic Deep Water (NADW) production. Likewise, as the new stadial progressed, the removal of freshwater from the North Atlantic by land ice growth and a southward-shifted ITCZ in a cooler Northern Hemisphere climate would result in increased salinification of the subtropical North 
Atlantic. This would drive the system back into an interstadial state with a resultant net negative surface buoyancy flux being applied over the high latitude North Atlantic, thereby reactivating NADW production. Broecker et al. (1990) referred to his mechanism as involving a "salt oscillator."

Based upon the existing paleoceanographic evidence (e.g., Henry et al. 2016), significant changes in the Atlantic meridional overturning circulation (AMOC) are widely believed to have played a critical role in marine isotopic stage 3 (MIS3) D-O-related climate variability. While there currently remains little doubt that the AMOC plays a major role in the dynamics of the D-O cycle, there have previously been numerous attempts to explain the underlying dynamics with different models of modest complexity. Some of the semiquantitative ideas that have been suggested to provide an explanation of the D-O process have invoked internally generated AMOC "loop" or "deep decoupling" oscillations (e.g., Malkus 1972; Welander 1986; Winton and Sarachik 1993; Weaver and Hughes 1994; Sakai and Peltier 1995, 1996, 1997; Colin de Verdière et al. 2006; Colin de Verdière 2007; Sévellec and Fedorov 2015). Other suggested mechanisms have relied upon noiseinduced freshwater flux variations or an oscillator involving stochastic processes (e.g., Timmermann et al. 2003; Stastna and Peltier 2007; Kleppin et al. 2015). Hysteresis in the climate system has also been suggested to be the mechanism at the heart of the underlying dynamics of the glacial D-O process (Broecker et al. 1985; Rahmstorf 2002; Zhang et al. 2014, 2017). Others have investigated the properties of the D-O oscillation by comparing records of glacial climate variability with simple dynamical systems models that support relaxation oscillation behavior (Rial and Yang 2007; Rial and Saha 2011; Shao and Ditlevsen 2016). Recent studies using both an ocean box model coupled to a simple thermodynamic sea ice model (Saha 2015) and a dynamical systems model (Roberts and Saha 2017) that arises from reformulations of the Stommel model (Stommel 1961) exhibit relaxation oscillations that respond to variations in insolation and freshwater forcing and qualitatively mimic the observed record. A further study has compared the observed climate record with stochastic dynamical systems models that have either a double-well potential or self-sustained oscillator form (Mitsui and Crucifix 2016). That study suggested that the self-sustained relaxation oscillator form is more robust compared with the observed record under variations in insolation and ice sheet size. The relationship between Heinrich events and the D-O cycle has also been the subject of active discussion (Sakai and Peltier 1997, 1999; Timmermann et al. 2003; Shaffer et al. 2004;
Peltier and Vettoretti 2014; Saha 2015; Roberts and Saha 2017; Bassis et al. 2017).

Recently Peltier and Vettoretti (2014, hereafter PV14) have demonstrated that the D-O oscillation arose naturally in a slightly modified but fully coupled version of the NCAR Community Climate System Model, version 4 (CCSM4), under fixed glacial boundary conditions and at full CMIP5 $1^{\circ} \times 1^{\circ}$ resolution for both the atmosphere and ocean (see the model and methods section below). The simulations of PV14 are especially important as they enable for the first time a detailed analysis of the mechanisms involved in the D-O oscillation phenomenon. In particular, the millennium time-scale oscillatory behavior that this model delivered was shown to develop spontaneously subsequent to a Heinrich event-like sharp decrease in the strength of the AMOC and in the absence of any stochastic component of the forcing. Furthermore, the oscillatory behavior that thereafter ensued did not require any covariation of freshwater forcing associated with land ice melting or growth to sustain it. This demonstrated that the basic mechanics of the oscillation involved a nonlinear self-sustained free oscillation of the coupled atmosphereocean-sea ice system rather than one forced by freshwater exchange between grounded ice on the continents and the Atlantic Ocean. Nevertheless, variations of salinity were shown to be fundamental to the D-O behavior, which was referred to in PV14 as involving the action of a "kicked" salt oscillator in the Atlantic, the kick required to trigger the oscillatory behavior being provided by a Heinrich event. The oscillation was also shown to be tightly coupled to North Atlantic sea ice cover.

A number of previous studies had also suggested the possible importance of sea ice and of subsurface warming of the water column beneath a stadial halocline to understanding of the abrupt transition that is characteristic of D-O warming events (Rasmussen and Thomsen 2004; Li et al. 2010; Dokken et al. 2013; Singh et al. 2014; Saha 2015). Vettoretti and Peltier (2016, hereafter VP16) were able to demonstrate through a diagnostic analysis of the CCSM4 simulation of the D-O cycle that the rapid warming transitions were associated with the onset of convective destabilization of the water column beneath the stadial sea ice lid. However, the instability was demonstrated to consistently occur in the Irminger Sea basin where it was associated with the opening of an enormous "super polynya." Although deep water formation under modern climate conditions occurs in the Greenland-Iceland-Norwegian (GIN) and Labrador Seas, under glacial conditions the reinvigoration of the MOC across the stadial to interstadial transition occurs mainly in the Irminger Sea basin as we will further discuss herein. VP16 further suggested that anomalous salt intrusion into the surface mixed layer of 
the North Atlantic polar halocline at the termination of stadials was the primary destabilizing factor that is involved in the instability, which drives the transition from cold stadial to warm interstadial conditions. Other factors that may also be important in the onset of D-O warming events were suggested to possibly involve a contribution to the convective instability of the water column associated with cabbeling and thermobaric instability arising from the nonlinearity of the equation of state of seawater (Adkins et al. 2005; VP16; Su et al. 2016).

One of the main contributions of the present paper will involve a detailed discussion of the importance of the significant accumulation of sea ice in the Arctic Ocean basin that occurs (in the model) under cold glacial conditions. In this context it is useful to note the paper of Bradley and England (2008) in which the notion that "paleocrystic" sea ice (sea ice of great age) might have been involved in the initiation of the Younger Dryas (YD) return to cold conditions. However, this transition at the end of the deglaciation event from MIS2 to the Holocene has since been established as having been forced by an intense freshwater outflow into the Arctic Ocean through the Mackenzie River outlet (Tarasov and Peltier 2005; Murton et al. 2010). Nevertheless, this freshwater would most probably have been delivered to the GIN Seas by the export of pack ice through Fram Strait as in the suggestion of Bradley and England (2008) for YD onset. The role of Arctic freshwater export by sea ice transport into the North Atlantic will be demonstrated in what follows to be a significant contributor to the mechanics of the D-O oscillation. Here we will build upon the previously discussed diagnostic analyses of the D-O oscillation (see model and methods section below). In the first part of the results section below, we compare the simulation of Arctic sea ice in the D-O oscillation with inferences of perennial Arctic sea ice cover during MIS3 as previously described using an appropriate and somewhat novel proxy for sea ice cover in the north polar ocean. In the following subsections of the results section, we will discuss further analyses of the physics involved in the two distinct phases of D-O relaxation oscillations. In particular, we will discuss the physics that determine the slow-timescale phase of the transition from warm interstadial to cold stadial conditions and those that control the fasttime-scale reverse phase of each of these cyclic oscillations. The methodology we have been employing in these analyses is discussed in the following subsection.

\section{Model and methods}

The original simulation of the D-O phenomenon in PV14 was based upon the use of the CCSM4 (Gent et al.
2011). This global coupled model of approximately $1^{\circ} \times 1^{\circ}$ horizontal resolution employs CAM4 and POP2 as the atmosphere and ocean components, respectively. The sea ice dynamics is represented by the Los Alamos model CICE4. The glacial climate experiments employ fixed ice age boundary conditions provided by the ICE6G_C (VM5a) model for paleotopography, paleobathymetry, and land ice cover (Argus et al. 2014; Peltier et al. 2015) for nominal Last Glacial Maximum [LGM at $21 \mathrm{ka}$ before present (BP)]. Since actual LGM was approximately $5 \mathrm{kyr}$ earlier at $26 \mathrm{ka}$ (Peltier and Fairbanks 2006) it is not expected that the 21-ka ice cover in ICE-6G_C (VM5a) will differ significantly from that in MIS3 insofar as the phenomenology of interest is concerned. Orbital insolation and trace gas concentrations are also fixed to those appropriate to $21 \mathrm{ka} \mathrm{BP}$. The boundary and initial conditions for these simulations have been discussed in detail previously in Vettoretti and Peltier (2013) and PV14, and it is clear that the initial conditions employed in these analyses were especially important to the successful simulation of the D-O process. The simulation to be analyzed in great detail herein was run for 5000 calendar years and was initially presented in the supplementary materials section of PV14. In this section of PV14 the impact of a more realistic parameterization of diapycnal diffusivity was also explicitly implemented in order to provide a comparison with the simulation employed in the main text of that paper in which a constant background pelagic value of diapycnal diffusivity was employed throughout the volume of the oceans.

The ocean vertical mixing parameterization employed in the Los Alamos ocean model POP2 is the K-profile parameterization (KPP) described in Large et al. (1994) with modifications described in appendix A of Danabasoglu et al. (2006) and Jayne (2009). The Large et al. (1994) interior tracer diffusivity and momentum diffusivity consists of terms arising from contributions from parameterized shear instability, parameterized doublediffusive convection and salt fingering, and mixing due to the action of an assumed background internal waverelated mixing field. The vertical momentum diffusivity employed in the model is calculated from the vertical tracer diffusivity based upon the assumption of a turbulent Prandtl number of 10. The Gent and McWilliams (1990, hereafter GM) parameterization of isopycnal eddy diffusivity that is employed to model the quasiadiabatic interior is not valid near the surface. Therefore, the GM parameterized eddy fluxes are replaced by a different near-surface eddy flux parameterization (Ferrari et al. 2008). Here the mixed layer depth (MLD) represents a low-frequency time-filtered envelope of the surface boundary region and records the maximum 
depth of the boundary layer after sustained deep mixing events. Some of the further modifications in the POP2 implementation of the Large et al. (1994) KPP parameterization include the addition of effects of increased vertical mixing in the deep ocean due to the enhancement of an internal wave-breaking-related energy field resulting from the flow of the barotopic tide over bottom topography. The modern-day prescribed internal wave energy field due to tidal mixing is turned off in our analyses because the mixing energy fields that are applicable during the glacial could not have been the same as those that were operative under modern conditions and to which the tidal mixing parameterization in POP2 was tuned. This is simply because the glacial tidal regime differed dramatically from the present regime (Griffiths and Peltier 2008, 2009). The vertical tracer diffusivity and momentum diffusivity profiles have been replaced in our simulation of the D-O oscillation by the same globally uniform vertically varying profiles that were employed in POP1 [similar to the Bryan and Lewis (1979) profile but with a transition depth at $1000 \mathrm{~m}$ instead of $2500 \mathrm{~m}$ ]. This vertically varying profile in POP1 captures the increase of diapycnal diffusivity below the main thermocline (to a value of $\kappa=10^{-4} \mathrm{~m}^{2} \mathrm{~s}^{-1}$ ) that has been argued to be necessary to enable the deep water that forms at the poles to upwell throughout the ocean so as to close the overturning circulation. This profile then tapers to a pelagic value of $10^{-5} \mathrm{~m}^{2} \mathrm{~s}^{-1}$ as the surface is approached (e.g., Munk 1966).

The Los Alamos Sea Ice Model and its implementation in CCSM4 is described in detail in Hunke and Lipscomb (2010) and Jahn et al. (2012). The Arctic and Antarctic sea ice packs are a mixture of open water, thin first-year ice, and thick multiyear ice. The sea ice model has several interacting components including both thermodynamic and dynamic processes, as well as a transport model and a ridging parameterization. The thermodynamic model computes local growth rates of ice due to vertical fluxes of energy associated with convection, turbulence, and radiation. This sea ice model includes a multiple-layer snow model that includes a snow thickness growth rate that is due to the interaction of snowfall and vertical radiative fluxes. The model of ice dynamics predicts the velocity field of the ice pack based on a model of the rheology of the ice. The transport model calculates the advection of the areal concentration, ice volume, and other state variables. The sea ice model also includes an ice ridging parameterization that transfers ice among different thickness categories. When the ocean temperature drops below the freezing point of seawater a certain amount of frazil ice is formed. Runoff from rain and melting snow, water melted from or frozen to the bottom of the sea ice, and brine inclusion or rejection are incorporated in the freshwater balance of the sea ice and ocean systems. Other notable features important to this study include a sea ice age tracer that is employed explicitly in the diagnostic analysis that follows.

\section{Results}

\section{a. The simulated $D-O$ oscillation}

Temperature variations inferred from the stable oxygen isotope ratio $\left(\delta^{18} \mathrm{O}\right)$ in ice cores retrieved from Summit Greenland [e.g., North Greenland Ice Core Project (NGRIP)] have provided high-temporal-resolution time series of the climate variability that has occurred at high northern latitudes during the last glacial cycle (e.g., Huber et al. 2006). During MIS3, the oxygen isotopebased temperature reconstruction at NGRIP for a segment of the record (Fig. 1a) is characterized by the classic saw-toothed signal of the D-O oscillation. Each pulse of the observed signal begins with a rapid temperature jump from cold to warm conditions of between $10^{\circ}$ and $15^{\circ} \mathrm{C}$, which is followed by a slow return to cold conditions usually within 500 to 1500 years. Although the amplitude of the individual temperature oscillations is well explained by the model (Fig. 1b), it will be observed that the period of the oscillation produced by this particular version of the model is somewhat shorter and of (arguably) slightly lower amplitude. In the present paper, we will not address these remaining differences, which are being reserved as target for further analyses to be discussed elsewhere; rather our intention here is to focus upon the slow physics and fast physics underlying the origins of the relaxation oscillation form of an individual D-O cycle as highlighted in Fig. 1c. It is notable that the sequence of D-O oscillations delivered by the model subsequent to a Heinrich event-like reduction in the strength of the Atlantic MOC constitute an almost perfect "limit cycle" in which the pulse shape of each oscillation is almost identical. Given the complexity of the model we are employing, this should be seen as especially interesting. As previously mentioned it is also important to understand that the boundary conditions of land ice cover, paleotopography, and paleobathymetry are held fixed in these simulations. As commented in PV14 we expect that land ice cover would actually have reacted to the individual warming events and this would be expected to destroy the perfection of the limit cycle, an influence that we will discuss elsewhere. In the next subsection we will begin by illustrating the state of the ocean cryosphere through the D-O cycle at high northern latitudes. This will be followed by a discussion of results that focus upon the interstadial-to-stadial return 


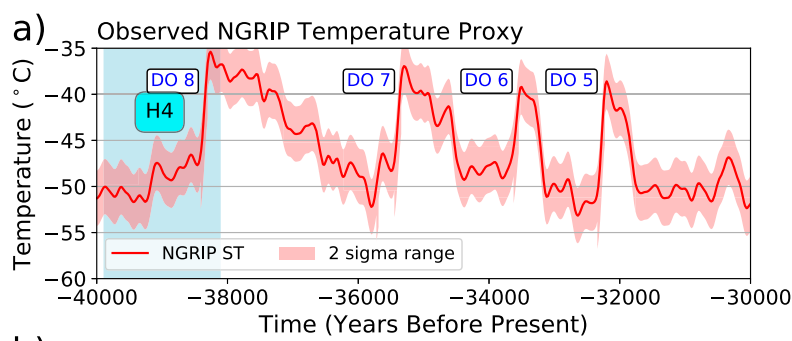

b) CCSM4 Model NGRIP Surface Temperature

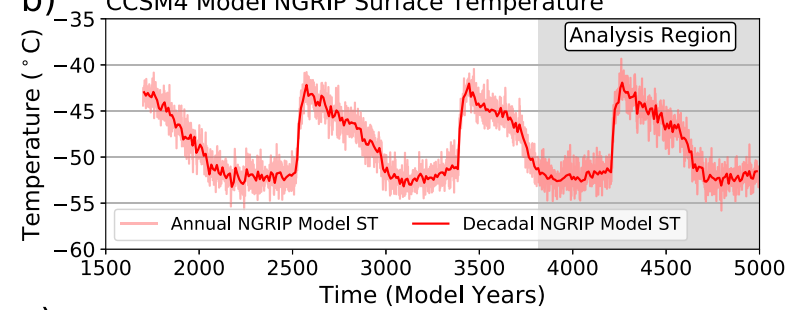

C) CCSM4 Model Analysis Region

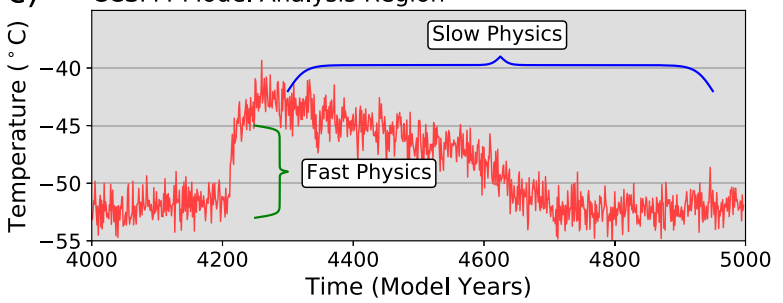

FIG. 1. (a) Observed surface temperature variations at NGRIP during the latter part of MIS3 (Huber et al. 2006). Heinrich Event 4 (H4: Zhou et al. 2014) and D-O cycles 8 through 5 are indicated in blue as well as the 2-sigma standard deviation in temperature (light red). (b) Annual (light red) and decadal mean (red) modeled NGRIP surface temperature variations. A segment of the model simulation from 4000 to 5000 years is highlighted in light gray. (c) This region constitutes the discussion of the fast and slow physics segments of the analysis.

from warm to cold conditions that occurs on a slow time scale, following which a discussion of the stadial-tointerstadial transition from cold to warm conditions that occurs on the fast time scale (Fig. 1c) will be provided.

\section{b. The cryosphere of the glacial ocean}

A valuable proxy that can be employed to assess past sea ice coverage over a range of scales from a state of open ocean to a state of perennial sea ice-covered ocean has recently been employed to infer millennial-scale variations in sea ice cover during the glacial period (Hoff et al. 2016). The C25 isoprenoid lipid (IP25) is a stable organic compound synthesized mainly by a few sea ice diatom species that provides a useful indicator of sea ice cover through the Quaternary (Knies et al. 2014; Manurung 2016; Stein and Fahl 2013). These IP25 analyses (Hoff et al. 2016) as well as other proxy studies (Cronin et al. 2010; Xiao et al. 2015) strongly suggest that during MIS3 stadials and interstadials, the Arctic was completely covered by perennial sea ice and that it possibly extended far across the Greenland-Scotland Ridge (GSR) and into the North Atlantic. This is entirely consistent with our detailed simulation of the D-O process.

The spatial distribution of stadial sea ice area (Fig. 2a) is characterized by a massive Northern Hemisphere polar halo with large portions of the high-latitude North Pacific covered with sea ice and North Atlantic sea ice reaching southward of $50^{\circ} \mathrm{N}$ latitude, as far south in the Eastern Atlantic as the south coast of the Bay of Biscay. The interstadial sea ice distribution (Fig. 2b) also shows that the Arctic remains fully ice covered throughout the entire D-O cycle consistent with the abovementioned paleo proxy data. During stadial conditions, the mean thickness of sea ice (Fig. 2c) in the Arctic Ocean is approximately 24 to $30 \mathrm{~m}$ with maxima upward of $40 \mathrm{~m}$ along the coastal margins of the Arctic basin according to our model. The interstadial sea ice distribution (Fig. 2b) is somewhat similar to the modern-day distribution, but the Arctic sea ice thickness is approximately $10 \mathrm{~m}$ (Fig. 2d) and still contains substantial multiyear sea ice. In Figs. 2c,d, the Arctic sea ice extrema are associated with points of runoff from the land surface model that are in both liquid and solid form (not shown). The solid form is due to the capping of the amount of snowfall accumulation that is allowed to occur over the portion of the land surface that is covered by the grounded continental ice sheets.

It is reasonable to imagine that, during the glacial, river runoff into the Arctic Ocean from the Siberian sector of the Eurasian continent and ice streams from both the Laurentide and Barents Sea ice sheet complexes would have provided a source of freshwater for sea ice formation at various seed points such as those depicted in Fig. 2. The land surface model employs an explicit river transport scheme that follows elevation changes to the ocean in such a way as to maintain a global salinity balance and thereby prevent salinity drift in the ocean component of the coupled model. The glacial modification of the modern-day river transport model due to the presence of land ice sheets was described in Vettoretti and Peltier (2013) and PV14. While a river transport model is clearly not realistic over an ice sheet it may nevertheless provide a representation of ice and water runoff from the large continental ice sheets that provide seeding points for the generation of vast amounts of paleocrystic sea ice during the D-O cycle (without modifying the paleotopography associated with the grounded ice thickness distribution). The magnitude of this runoff falls within the modern range of present-day runoff, and the implication of its effect on the D-O relaxation oscillation is discussed in greater detail in what follows. 

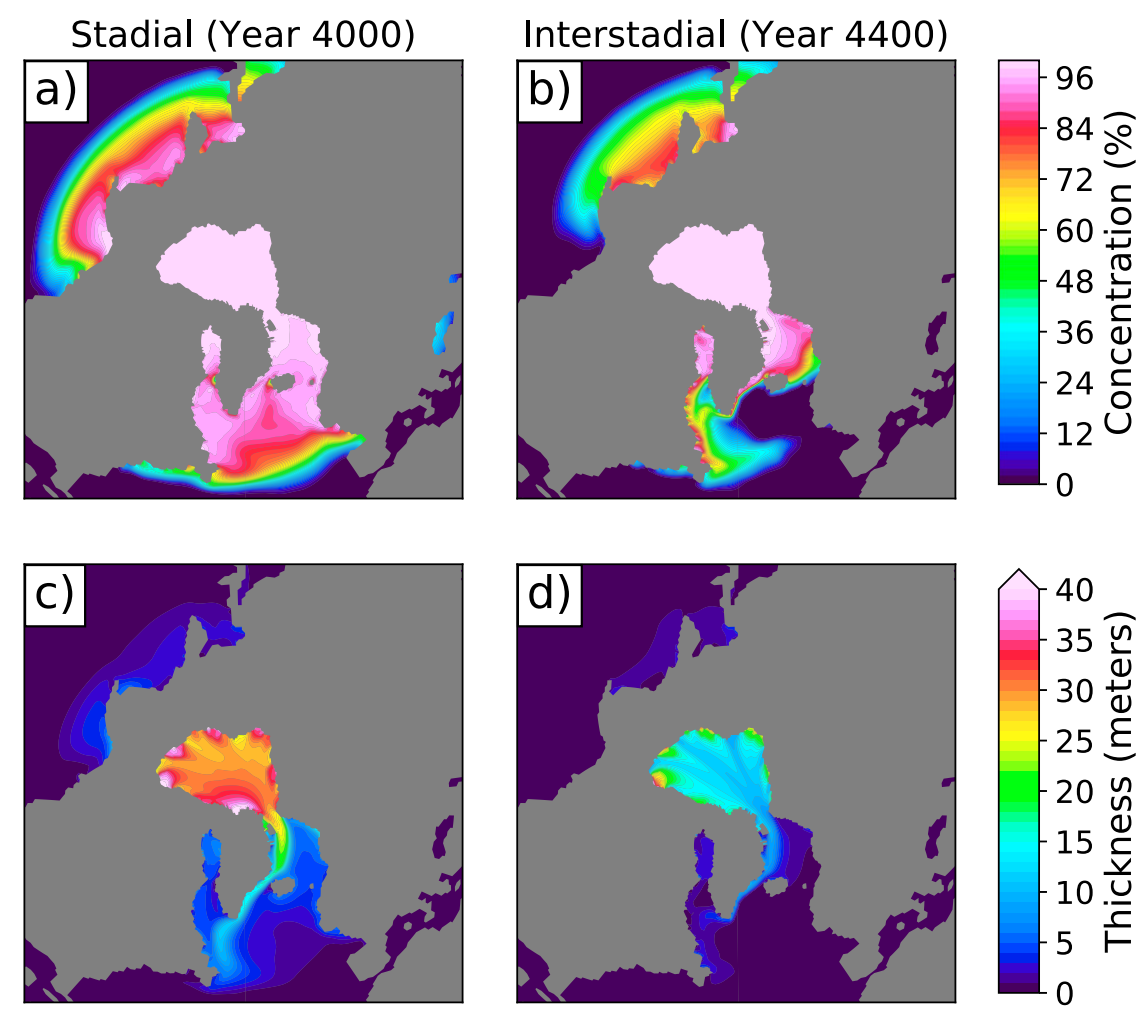

FIG. 2. Decadal averaged sea ice concentration (\%) for the (a) stadial and (b) interstadial. Decadal average sea ice thickness (meters) for the (c) stadial and (d) interstadial.

It is clear from the stadial sea ice age spatial distribution that these seed points drive a flow of old sea ice (Fig. 3) that is eventually transported by the Arctic anticyclonic surface circulation through Fram Strait into the East Greenland Current (EGC) region and eventually into the region under the control of the subpolar North Atlantic gyre circulation. It is interesting that the stadial mid-North Atlantic between $45^{\circ}$ and $50^{\circ} \mathrm{N}$ contains sea ice that is more than 20 years old (Fig. 3a). During the interstadial, this region still contains significant multiyear sea ice (Fig. 3b) according to the model. Some of the sea ice around the margins of the Arctic basin reaches more than 100 years in age during the stadial phase. There is also a significant southward transport of freshwater by paleocrystic sea ice into the North Atlantic mainly along the EGC and through Denmark Strait (DS) (Figs. 3c,d). This transport reaches south of $50^{\circ} \mathrm{N}$ latitude and is most intense from DS to the southern tip of Greenland in both the stadial (Fig. 3c) and interstadial (Fig. 3d). Transports of freshwater by the sea ice are larger in areal coverage during the stadial, but the intensity is stronger during the interstadial along the EGC. Interstadial transports would help to establish significant sea ice and, owing to its melting from below, a freshwater cap over the North Atlantic that would inhibit convection and NADW formation as the interstadial to stadial transition slowly progresses. We quantify and expand upon the slow-time-scale evolution of this and related processes in the following subsection.

\section{c. Slow-time-scale dynamics}

\section{1) HydRography AND SEA ICE TRANSPORT DIAGNOSTICS}

Several ocean regions have been defined as a basis for the analysis that will be discussed in what follows (Fig. 4a). The subregions selected are partially based upon the CESM definitions of the ocean basins in the POP2 ocean model (POP2 reference manual; Smith et al. 2010). The North Atlantic is divided into a northern section and a southern section separated at approximately $52^{\circ} \mathrm{N}$ latitude. The five basins of interest in this study are the tropical and subtropical North Atlantic (green), the high-latitude North Atlantic including the Irminger Sea south of Iceland (blue), the Labrador Sea (purple), the GIN Seas (magenta), and the Arctic Ocean (cyan). The Arctic and GIN Seas are separated from the North Atlantic and Irminger Sea by the Greenland-Scotland Ridge, which includes the Denmark Strait and Faroe-Shetland Bank overflow 

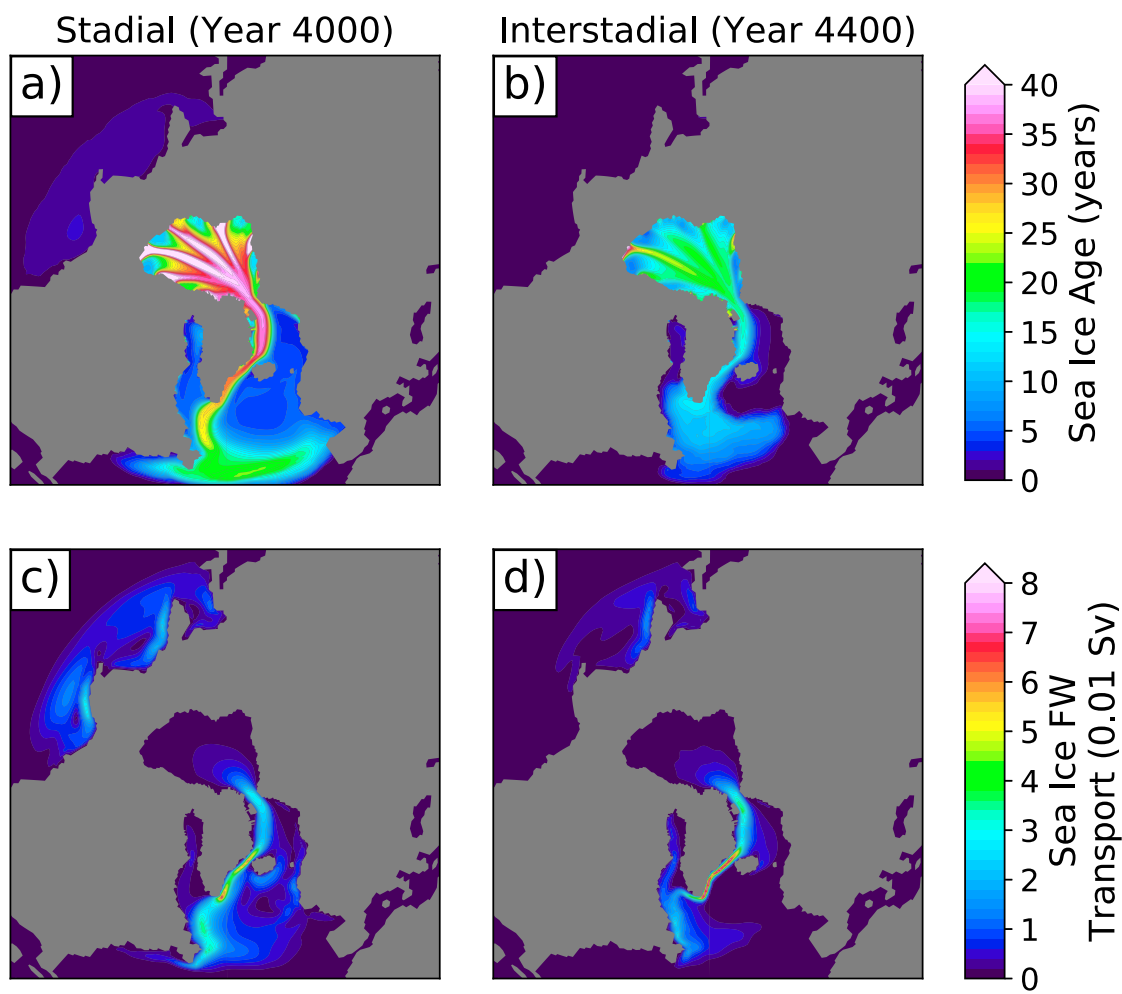

FIG. 3. Decadal average sea ice age (years) for the (a) stadial and (b) interstadial. Decadal average sea ice freshwater transport $\left[1 \mathrm{~Sv}=10^{9} \mathrm{~kg}\right.$ (water mass) $\left.\mathrm{s}^{-1}\right]$ for the (c) stadial and (d) interstadial.

channels. The Bering and Nares Straits are closed during glacial conditions due to the reduced eustatic sea level caused by the extraction of freshwater from the oceans that was required to build the grounded continental ice sheets with the global paleobathymetry fixed to that of the ICE-6G_C (VM5a) model (Peltier et al. 2015). Because of this, the Arctic and GIN Seas basins have a direct connection only with the North Atlantic basin.

The changes in mean volume averaged basin salinity in the subtropical North Atlantic basin and Arctic basin reveal their evolution to be almost perfectly anticorrelated (Fig. 4b). This low-latitude-high-latitude salinity oscillation will be shown to be an important characteristic of the structure of the D-O oscillation in the analysis to follow (see also PV14). Following the rapid $\mathrm{D}-\mathrm{O}$ warming event, the release of ocean convective available potential energy (VP16; Su et al. 2016) results in a cooling at depth of the ocean in the high North Atlantic and Labrador basins. Thereafter, both salt and heat (Figs. 4b,c) are transported into the North Atlantic north of $52^{\circ} \mathrm{N}$ by the reinvigorated AMOC (PV14), followed by a slow-time-scale cooling and freshening trend over the following 400 years until full stadial conditions develop. During the ensuing 400 years of the stadial, in this roughly $900-\mathrm{yr}$ oscillation, the high-latitude North Atlantic basin begins to gradually warm and become more saline below an expanding sea ice capped halocline. In the Arctic and GIN Seas basins there is no significant variation in potential temperature, which remains near the freezing point of seawater throughout the D-O cycle (Fig. 4c). This demonstrates that the transport of heat to the north by the AMOC never penetrates across the Greenland-Scotland Ridge into the GIN Seas. The potential density changes in the Arctic, GIN Seas, and high-latitude North Atlantic (Fig. 4d) reveal the influence of the nonlinearity of the equation of state of seawater in which the density at low temperature is controlled by salinity. Therefore, the $\mathrm{D}-\mathrm{O}$ oscillation is accurately characterized as a lowlatitude-high-latitude salt oscillation (PV14). The sea ice volume and sea ice age time series for the same highlatitude basins are characterized by a pronounced interstadial-stadial cycle (Figs. 4e,f). The enclosed glacial Arctic basin is seen to be aptly characterized as a factory for the production of "paleocrystic" sea ice during the stadial phase with only one outlet available to it through Fram Strait. The volume of sea ice in the combined Arctic and GIN Seas basins reaches $175000 \mathrm{~km}^{3}$ during peak stadial conditions (in this model). Immediately following the D-O warming event, 
a)

\begin{tabular}{|l|l|l|l|l|l|l|}
\hline Land & N.Atl $0-52^{\circ} \mathrm{N}$ & N.Atl $>52^{\circ} \mathrm{N}$ & Lab Sea & GIN Sea & Arctic & Other \\
\hline
\end{tabular}

)

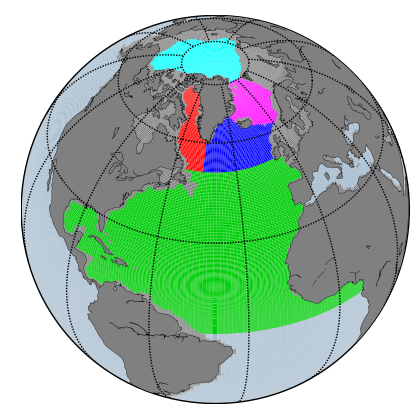

C)
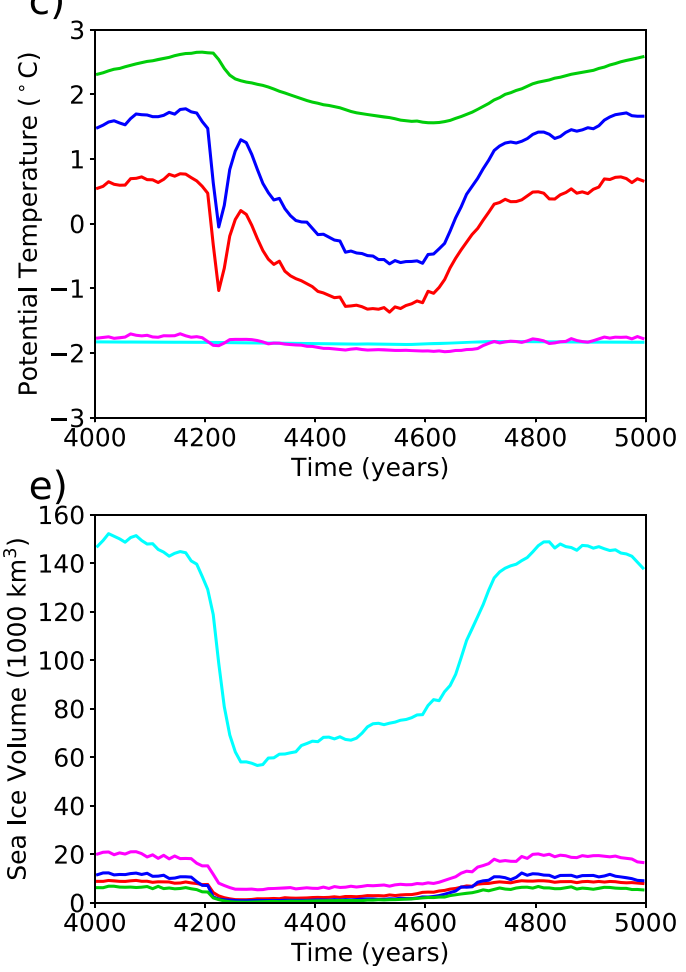

b)

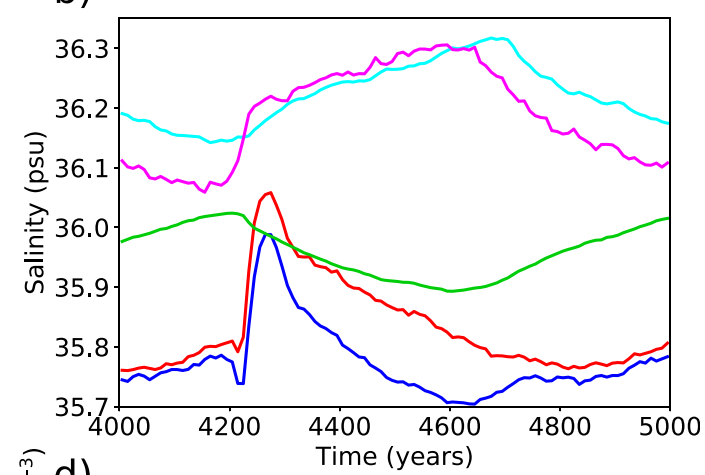

(1) d)

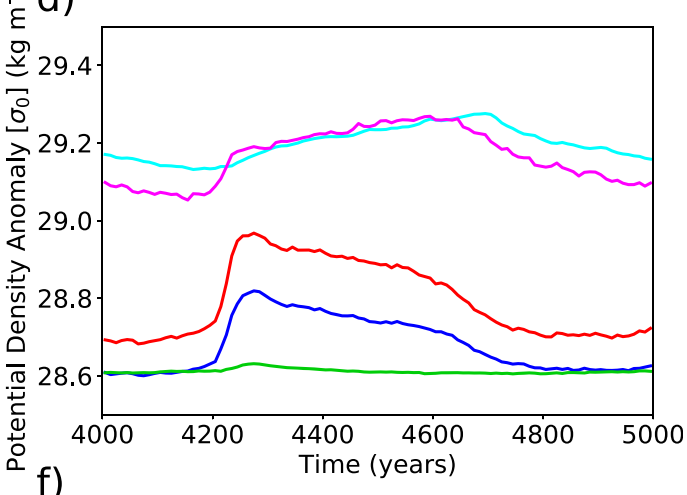

f)

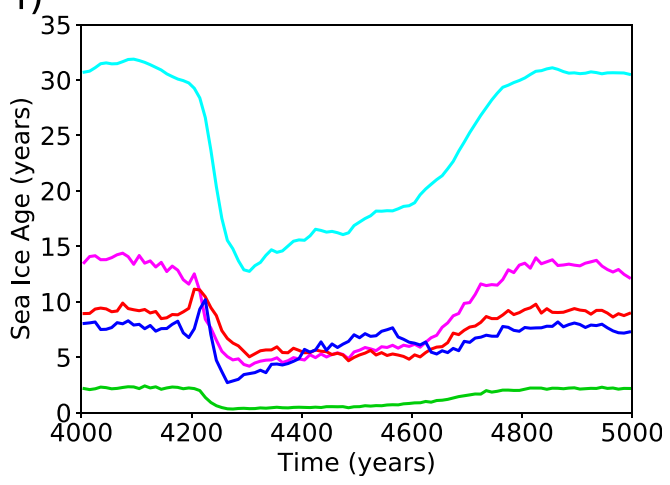

FIG. 4. (a) Ocean regions described in the paper: Arctic (cyan), GIN Seas (magenta), Labrador Sea (red), North Atlantic greater than $52^{\circ} \mathrm{N}$ (blue), and North Atlantic between the equator and $52^{\circ} \mathrm{N}$ latitude (green). The time series of volume-averaged (b) salinity, (c) temperature, (d) potential density anomaly (referenced to the surface), (e) sea ice volume, and (f) sea ice age in each of the five basins. The time series are color coded according to the regions in a).

the interstadial minimum is reduced to approximately half the stadial maximum (Fig. 4e). The average age of the sea ice in the Arctic basin is more than 30 years during the stadial phase (Fig. 4f).

A further characterization of the slow physics involved in the interstadial to stadial transition is provided by the time series of upper-ocean vertical profiles of horizontally averaged salinity, potential temperature, and Brunt-Väisälä frequency in each of the basins that are shown in Fig. 5. In the Arctic and GIN Seas much of the salinity increase occurs during the interstadial and at great ocean depth (not shown), the result of basin restratification during sea ice buildup and brine rejection. Although the low-latitude subtropical North Atlantic basin also experiences an increase of salinity, this occurs during the stadial period in the subtropical thermocline (PV14). The high-latitude North Atlantic is characterized by the establishment of a distinct halocline during the stadial with a fresh and cold surface layer beneath the sea ice overlying a warm 

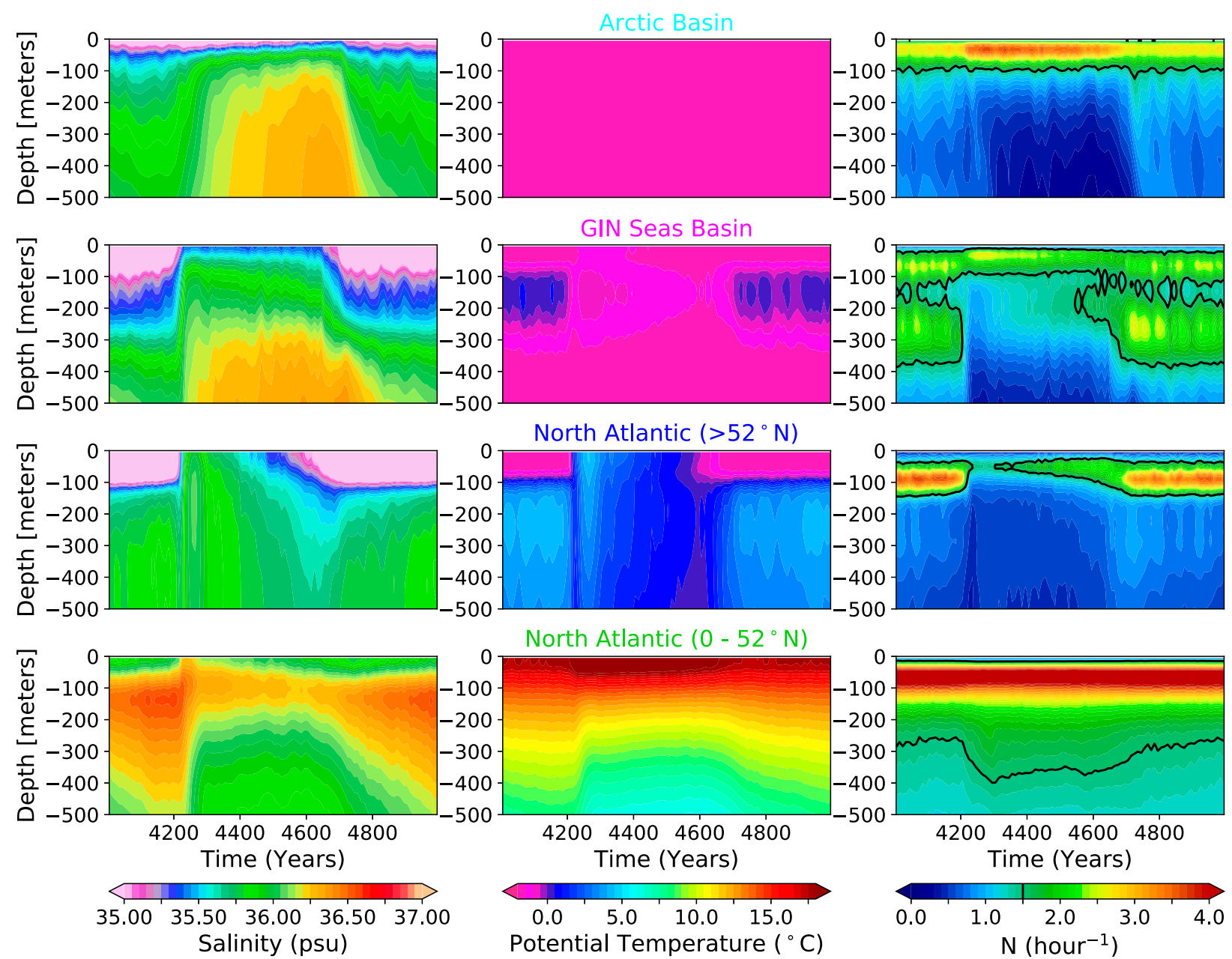

FIG. 5. Time series of the vertical profile of mean layer averaged basin salinity (psu), temperature $\left({ }^{\circ} \mathrm{C}\right)$, and Brunt-Väisälä frequency $(N)$ in the four ocean regions correspond to the basins from Fig. 4a. The $N=1.5$ cycles per hour isoline is displayed in black to indicate the approximate vertical thickness of the polar halocline in the high-latitude basins.

and salty Atlantic layer below, all within the first few hundred meters of the surface. As previously discussed in connection with Fig. 4, the temperature variations in the Arctic and GIN Seas are negligible at all depths. Likewise, the subtropical North Atlantic has minor variations in vertical temperature structure. This lack of significant temperature variations except in the highlatitude North Atlantic demonstrates that the slowtime-scale phase of the D-O cycle is governed by a salt oscillation as discussed in PV14. The densest waters are situated in the Arctic, and ocean density decreases southward with latitude (not shown). The nature of the slow restratification of the interstadial ocean can be further assessed by using the Brunt-Väisälä frequency as a proxy for a halocline stratification index in the pycnocline of the four high-latitude basins (Bourgain and Gascard 2011). This diagnostic is shown for each of the basins in the last column of graphics in Fig. 5. The surface stratification of the subtropical North Atlantic and Arctic remain relatively unchanging during the D-O cycle, where these low-latitude and high-latitude basins are controlled by temperature and salinity, respectively. The majority of the stratification changes between the interstadial and stadial occur in the GIN Seas and highlatitude North Atlantic. In particular, the high-latitude North Atlantic is characterized by the existence of a layer of strong stratification that grows in thickness as the transition into full stadial conditions progresses. Under full stadial conditions, the stratified layer stabilizes in thickness at approximately $100 \mathrm{~m}$ where it is present between 50- and 150-m depth, its development being diagnostic of the vertical temperature and salinity gradients characteristic of a strong sea ice-covered polar halocline somewhat similar to that which characterizes the ice-covered Arctic Ocean under modern climate conditions. 
a)

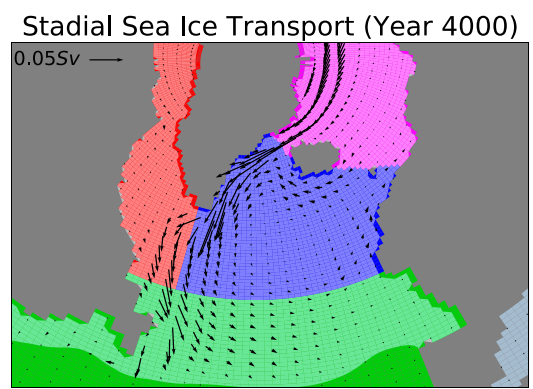

C)

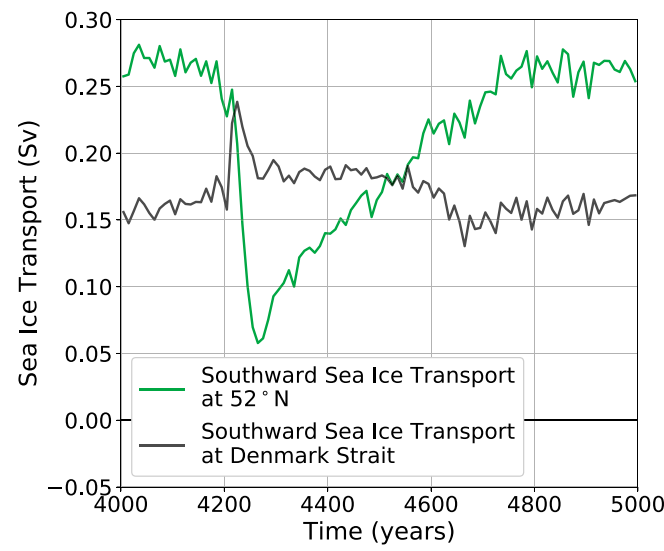

b)

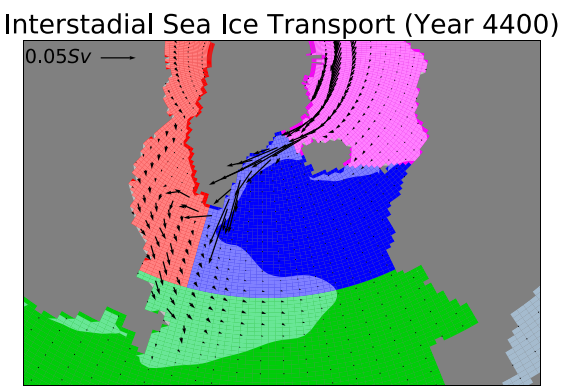

d)

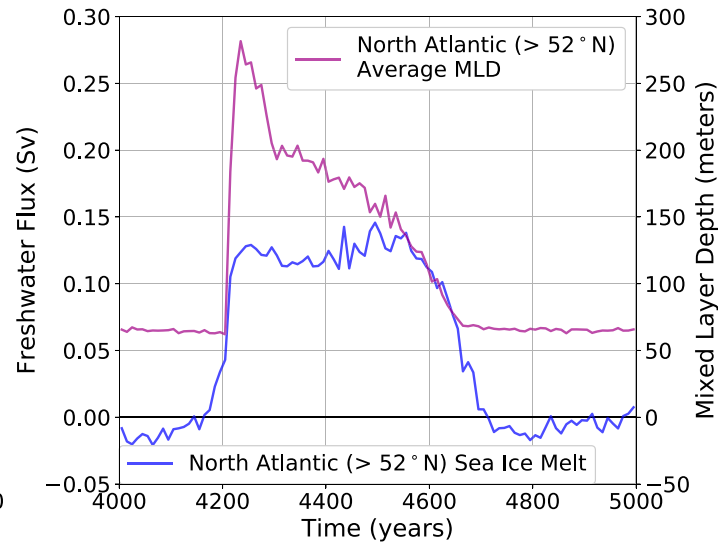

FIG. 6. The sea ice transport vector field (black arrows) during the (a) stadial and (b) interstadial over the GIN Seas (magenta), the Labrador Sea (red), the North Atlantic $>52^{\circ} \mathrm{N}$ (blue), and the North Atlantic $0^{\circ}-52^{\circ} \mathrm{N}$ (green). The white shading in (a) and (b) demarcates sea ice concentrations $>10 \%$. (c) The total southward sea ice transport through the Kögur Transect between Greenland and Iceland (black) and the total southward sea ice transport through the zonal transect spanning the entire North Atlantic at $52^{\circ} \mathrm{N}$ (green). (d) The mean convective activity as measured by the area-averaged mixed layer depth over the North Atlantic $>52^{\circ} \mathrm{N}$ (blue basin). Also displayed is the sea ice freshwater melt $(>0)$ over the same basin.

The sea ice transport from the Arctic basin into the Atlantic subpolar gyre may be usefully further investigated in order to emphasize the important role that sea ice plays in mediating the slow physics of the interstadial-to-stadial transition. To this end a vector plot of the sea ice transport over the high-latitude basins during the stadial (Fig. 6a) and interstadial (Fig. 6b) illustrates the continuously strong transport by the East Greenland Current (EGC) from the GIN Seas through the Denmark Strait and into the Irminger basin (IB) that persists during the D-O cycle. The mass transport of sea ice $\left[10^{9} \mathrm{~kg}\right.$ (water mass) $\left.\mathrm{s}^{-1}=1 \mathrm{~Sv}\right]$ through the Kögur Transect (the narrow strait between Greenland and Iceland) is characterized by a surprisingly constant southward flow of sea ice throughout the entire cycle. The stadial sea ice mass transport is approximately $0.15 \mathrm{~Sv}$, while that of the interstadial is approximately $0.18 \mathrm{~Sv}$ (Fig. 6c). The sea ice mass transport southward across the $52^{\circ} \mathrm{N}$ latitude zonal transect in the Atlantic is much more variable and is characterized by the familiar saw-toothed D-O structure. The transport across the $52^{\circ} \mathrm{N}$ zonal section is stronger than the Kögur Transect sea ice transport during the stadial but weakens considerably at the start of the interstadial and slowly regains stadial values over the next 500 years. This indicates that a significant amount of sea ice may be melting in the Labrador Sea or subpolar North Atlantic during the interstadial. Interestingly, the magnitude of freshwater input by melting sea ice to the North Atlantic basin remains relatively constant at approximately $0.13 \mathrm{~Sv}$ during the interstadial (Fig. 6d). The Labrador Sea basin on the other hand remains a very modest contributor to sea ice growth throughout the entire D-O cycle (not shown). The average mixed layer depth in the high-latitude North Atlantic basin decreases at a slow and relatively constant rate throughout the interstadial period as a constant sea ice melt flux is applied to this basin (Fig. 6d). As the sea ice coverage spreads over the high-latitude North Atlantic basin through the slow interstadial-stadial transition (Fig. 6a), the stadial halocline is reestablished. Therefore, the usual critical regions of convection and NADW formation 
(Marshall and Schott 1999) are eliminated by a slow physical process of sea ice mass transport from the Arctic through the EGC and then circulated cyclonically in the subpolar gyre as the interstadial progresses, thereby leading to complete coverage of the northern North Atlantic by the stadial sea ice "lid."

The hydrography of a particular ocean section that spans from the GIN Seas to the Labrador Sea (shown in Fig. 7) is next investigated in order to further diagnose the slow-time-scale interstadial-to-stadial restratification of the high-latitude North Atlantic basins. At the beginning of the interstadial (Fig. 7a), warm and salty water is transported to the high-latitude North Atlantic by the North Atlantic Current and subsequently by the Irminger Current. The relatively warm and salty anomalies persist to the south of Iceland uniformly in the upper $1000 \mathrm{~m}$ of the water column for several hundred years during the interstadial (Fig. 7b). This indicates active North Atlantic gyre and subtropical gyre circulations, as well as active deep water formation. As the sea ice cover expands over the high-latitude North Atlantic due to the action of the slow physical processes described above (Fig. 5), deep convection begins to become significantly impeded and the polar halocline is reestablished near the interstadialstadial transition (Fig. 7c). It is conceivable that a positive sea ice albedo feedback and air-sea flux feedback is contributing significantly at this stage of sea ice growth but this will not be further investigated here. Also during this interstadial-stadial transition stage, the temperature and salinity is at a minimum below the base of the mixed layer. Subsequently, the thermal reservoir located below $100 \mathrm{~m}$ depth, which is instrumental in destabilizing the stadial (VP16), slowly begins to build to more than $5^{\circ} \mathrm{C}$ as stadial conditions dominate the high-latitude North Atlantic (Fig. 5d). During this stadial period, with the full southward extent of the sea ice established, the largest salinities have built up in the deepest levels of the GIN Seas and remain isolated from the high-latitude North Atlantic by the Greenland-Scotland Ridge (Fig. 7d). Furthermore, a strongly stratified layer, that is clearly evident in terms of the layering of isopycnals, becomes firmly established at depth all along this hydrographic transect, setting the stage for the rapid stadialinterstadial transition. The dynamics of the slow-timescale reorganization of the salinity stratified water masses in the high-latitude basins is further described in the following paragraphs.

\section{2) QuAntitative Budget ANALyses}

Understanding the long-time-scale transports of salt in the ocean component of the climate system is complicated by source and sink terms in the individual ocean basins, which vary significantly over the D-O cycle (changes in the volume-averaged ocean basin salinity). When mass is added to the ocean by sea ice melt, rain, or river runoff the ocean redistributes the mass rapidly by ocean processes. Distinguishing between the transport of ocean water mass rather than the transport of freshwater anomalies may therefore be important [see Tréguier et al. (2014) for a discussion]. However, for the purpose of the analysis to be presented here we will employ a freshwater diagnostic measure to infer longtime-scale properties of the D-O oscillator because of the significant changes in net surface freshwater flux that are taking place in the high-latitude regions that are associated with sea ice melting. The freshwater mass transport through a zonal section $\left[A_{C}(x, z)\right]$ is expressed as follows (e.g., see Wijffels et al. 1992):

$$
\mathrm{FWT}=\oiint \rho_{0} v\left(1-\frac{\mathrm{S}}{S_{0}}\right) d A_{c} .
$$

Here the potential density referenced to the surface $\rho_{0}$, meridional velocity $v$, and reference salinity $S_{0}$ are used to calculate this total freshwater transport.

The overall zonally averaged freshwater flux at the surface of the Atlantic can be used to diagnose the critical regions of divergence and convergence of freshwater transport (Talley 2008). For example, in the tropics, there is a surplus of freshwater that is associated with the excess of precipitation over evaporation $(P-E)$. In the Atlantic subtropical gyre, the opposite is true, and the significant removal of freshwater from this ocean region is the source of a strong feedback that reinvigorates the AMOC at the start of the D-O interstadial (PV14). Therefore, there is a convergence of ocean freshwater transport into the Atlantic subtropical gyre region throughout the $\mathrm{D}-\mathrm{O}$ cycle centered at approximately $20^{\circ} \mathrm{N}$ (Fig. 8a). In the midlatitude North Atlantic, there is also a convergence of freshwater due to the southward transport and melting of sea ice during the stadial and interstadial and therefore a net flux of freshwater from sea ice to ocean (not shown). A critical aspect of the D-O salt oscillator is the Atlantic highlatitude northward ocean transport of freshwater into the subpolar and polar region that must compensate the removal of freshwater by the southward transport of sea ice (Fig. 8a). The extent of this effect is strongest during the stadial and operates from the high to midlatitude Atlantic during this segment of the D-O cycle. During the interstadial, this effect operates at higher polar latitudes, similar to what is observed under modern climate conditions (Aagaard and Carmack 1989).

Our previous analyses of the D-O phenomenon in this model have suggested that the atmosphere and ocean, acting together, may play an important role in the 

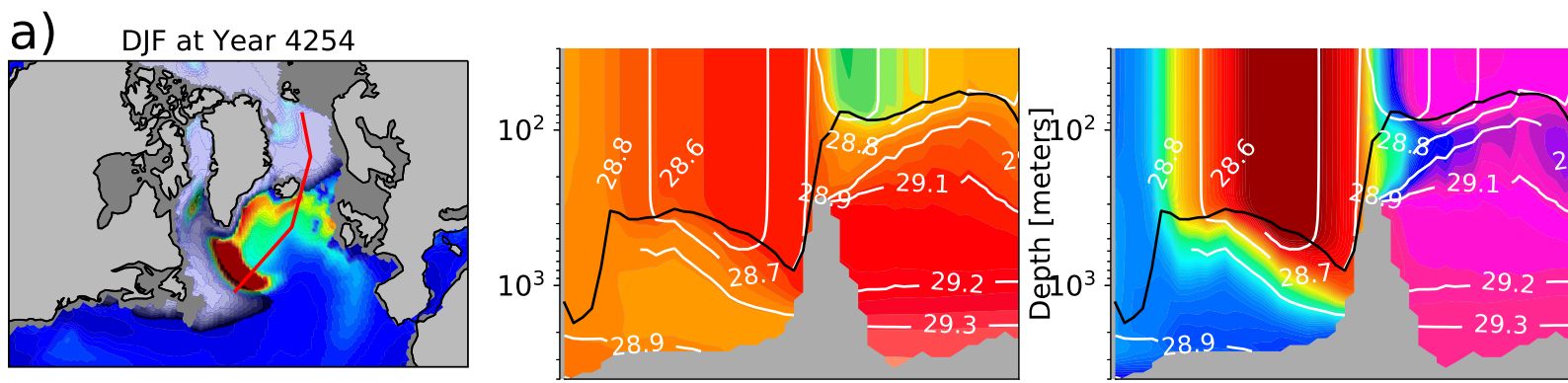

b) DJF at Year 4404
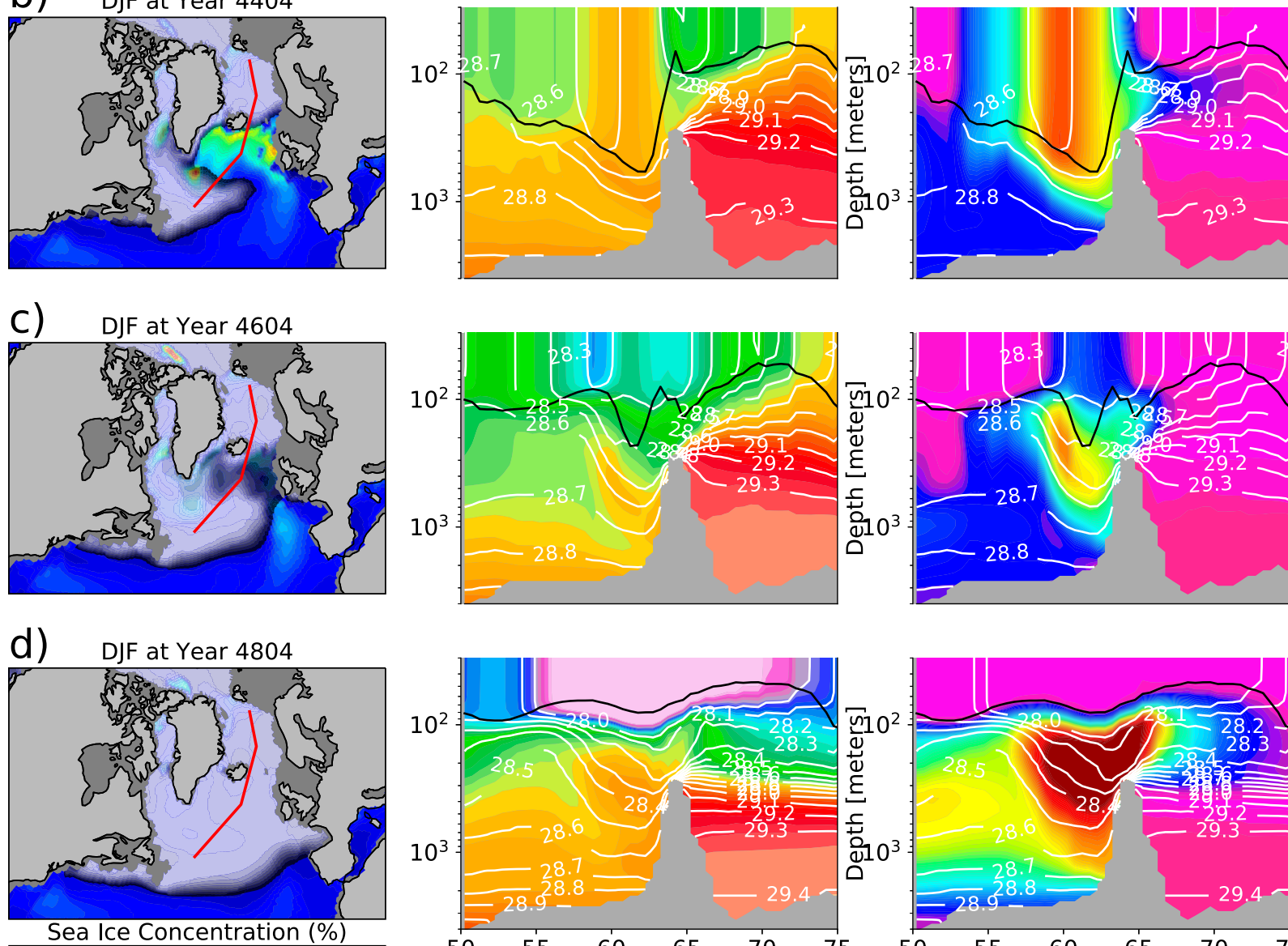

102030405060708090100
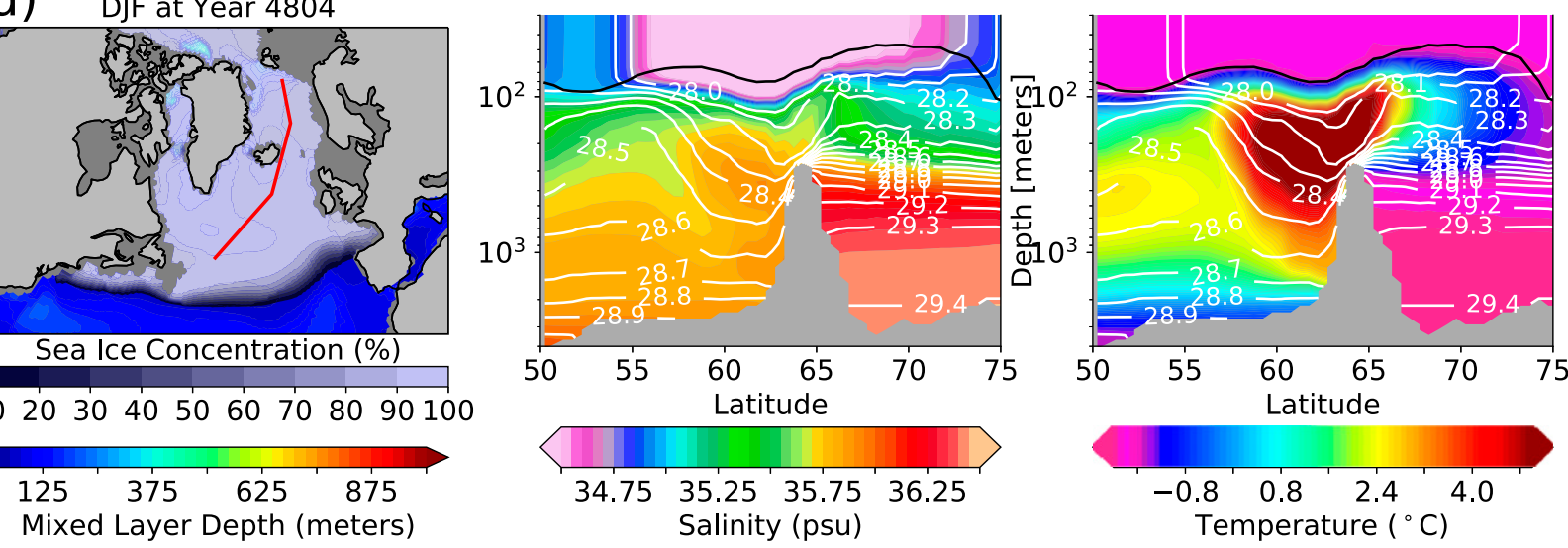

FIG. 7. Winter (DJF) (left) sea ice concentration and (center) hydrographic sections of salinity and (right) temperature through a vertical transect demarcated by the red line that runs from the North Atlantic into the GIN Seas. The slow evolution of the sea ice concentration, salinity, and temperature are shown for decadal averages (a) immediately after the warming transition at year 4254 and at years (b) 4404, (c) 4604, and (d) 4804. Potential density anomaly isopycnals are displayed in white contours and the mixed layer depth contour is displayed in black. The vertical axis is on a log scale running from 30 to $2500 \mathrm{~m}$.

propagation of interhemispheric temperature anomalies between the northern and southern polar regions, the so-called bipolar seesaw. The initial analysis of the results of our global model demonstrated that it captured this bipolar connection in a highly accurate fashion (PV14), and in a subsequent analysis (Vettoretti and Peltier 2015) the mechanism involved was further investigated. It is important to more fully 

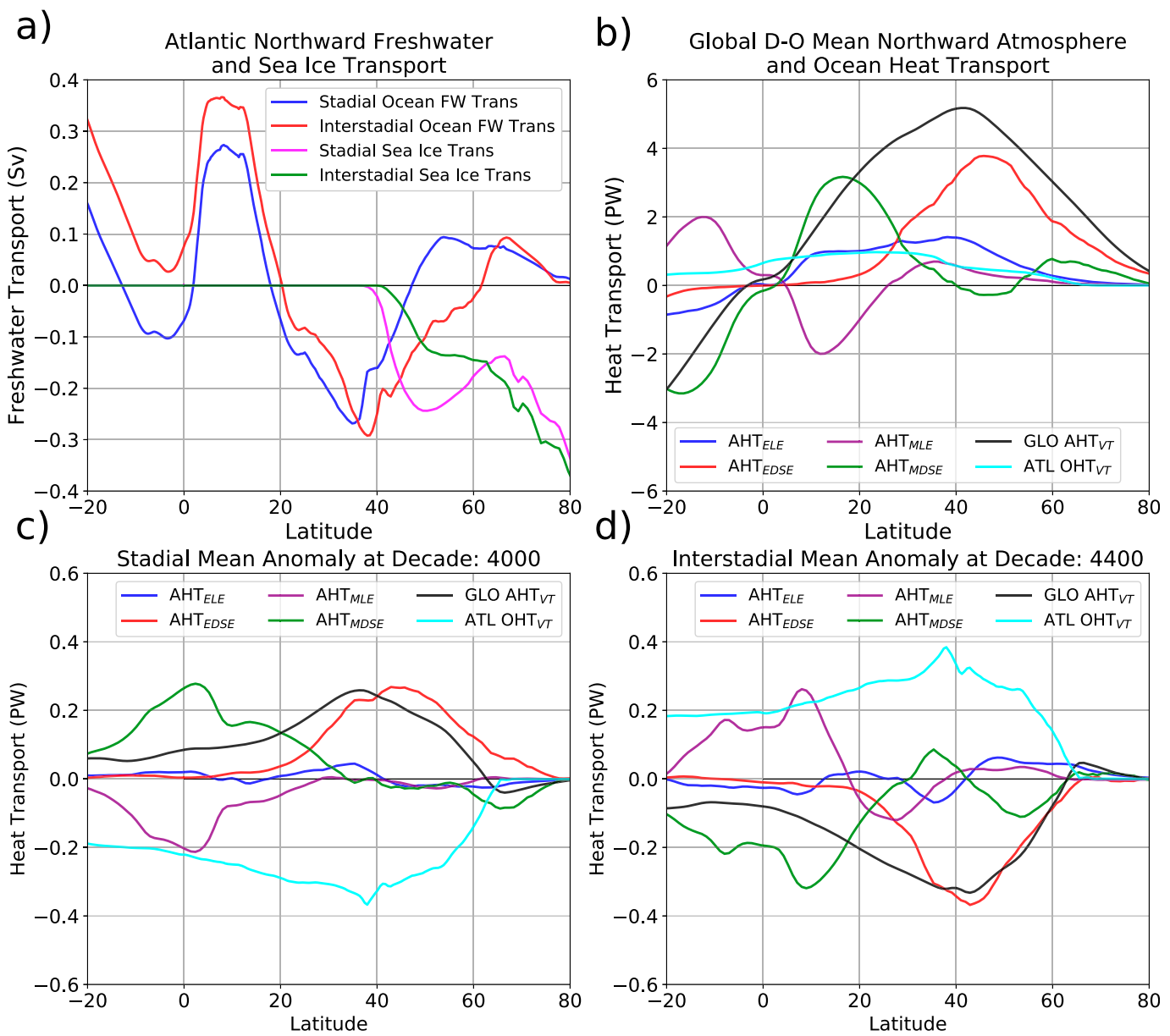

FIG. 8. (a) Atlantic and Arctic basin meridional freshwater transport (Sv) by the ocean and sea ice during the stadial and interstadial. (b) The average D-O cycle (over 850 years) atmospheric (black) and ocean heat transport (cyan). The mean meridional (purple: dry static energy; green: latent heat energy) and eddy atmospheric heat transports components (blue: DSE; red: LE) for the average of the D-O cycle are also shown. (c) The stadial anomaly (stadial - mean) of the same components in (b). (d) The interstadial anomaly (interstadial-mean) of the same components in (b).

consider the role that the northward transport of heat by the ocean and atmosphere might play in the slowtime-scale physics of the D-O oscillation that is here under investigation. The total northward atmospheric heat transport (AHT) across latitude $\theta$ can be calculated from the atmospheric moist static energy [MSE; e.g., see Czaja and Marshall (2006) and Yang et al. (2015a)] budget as follows:

$$
\mathrm{AHT}=\int_{0}^{2 \pi} d \lambda \int_{p_{T}}^{p_{S}} \frac{\rho_{A}}{g}\left(c_{p} T+\Phi+L_{v} q\right) R \cos \theta v d p .
$$

The variables appearing in Eq. (2) include atmospheric temperature $T$, geopotential height $\Phi$, specific humidity $q$, meridional velocity $v$, atmospheric density $\rho_{A}$, heat capacity of the atmosphere $c_{p}$, latent heat of vaporization $L_{v}$, radius of Earth $R$, latitude $\lambda$, gravitational acceleration $g$, and pressure $p$. The meridional transport of MSE can be further decomposed into components due to the dry static energy (DSE $\left.=c_{p} T+\Phi\right)$ and the latent energy $\left(\mathrm{LE}=L_{v} q\right)$. These separate transport components may be usefully further decomposed into the transport due to the mean meridional circulation and that due to the combined stationary and transient eddy components: $\overline{v^{\prime} \theta^{\prime}}=\overline{v \theta}-\bar{v} \bar{\theta} ; \overline{v^{\prime} q^{\prime}}=\overline{v q}-\bar{v} \bar{q}$ (see, e.g., Yang et al. 2015a). Therefore, the AHT can be analyzed in terms of the following budget:

$\mathrm{AHT}=\mathrm{AHT}_{\mathrm{MDSE}}+\mathrm{AHT}_{\mathrm{EDSE}}+\mathrm{AHT}_{\mathrm{MLE}}+\mathrm{AHT}_{\mathrm{ELE}} \cdot$

On the right-hand side of Eq. (3), these terms are, respectively, the mean meridional dry static energy $\left(\mathrm{AHT}_{\text {MDSE}}\right)$, stationary and transient eddy dry static 
energy $\left(\mathrm{AHT}_{\mathrm{EDSE}}\right)$, mean meridional latent heat energy $\left(\mathrm{AHT}_{\mathrm{MLE}}\right)$, and the eddy latent heat energy $\left(\mathrm{AHT}_{\mathrm{ELE}}\right)$.

The total annual mean atmospheric heat transport, decomposed into the total, mean meridional components, and eddy components, is shown in Fig. 8b. The mean values in Fig. $8 \mathrm{~b}$ are computed as the average over one complete D-O cycle. Also included in this analysis for comparison purposes is the total Atlantic Ocean meridional heat transport, which is denoted as the Atlantic Ocean heat transport (OHT) on the same figure. The OHT in the Indo-Pacific region is omitted because the variations in the interstadial-stadial anomalies in this region are not of significant magnitude except in the equatorial and southern latitudes in the Indo-Pacific region (not shown). The Atlantic OHT dominates the global OHT in northern midlatitudes and high latitudes. Although the total meridional AHT is calculated on a global basis, this global transport is expected to impact the entire northern polar region as it is not impeded by the landmasses as is ocean heat transport. The key fact that follows from this analysis is that the northward component of the AHT in the mean D-O cycle is dominated by the MDSE in the tropics and subtropics and by the EDSE in the midlatitudes to high latitudes (Fig. 8b), a result that is not unexpected. The northward transport of MDSE is associated with the action of upper-level divergence of the Hadley circulation. The northward transport of EDSE is associated with the sensible heat transport associated with stationary and transient eddies, and will impact high-latitude sea ice formation during both stadial and interstadial conditions.

In Figs. $8 \mathrm{c}$ and $8 \mathrm{~d}$, respectively, the Hadley circulation is shown to strengthen under colder stadial climate conditions and weaken under warmer interstadial conditions and is influenced by the state of the OHT (Levine and Schneider 2011). The result of this is an increase of the northward transport of MDSE during the stadial and a decrease during the interstadial relative to the D-O cycle mean. At midlatitudes, a similar effect occurs with the northward sensible heat transport of the EDSE that increases (decreases) during the stadial (interstadial) due to enhanced (reduced) baroclinic wave activity and stationary wave forcing. The overall result is that the total transport of heat by the atmospheric increases during the stadial (Fig. 8c) and decreases during the interstadial (Fig. 8d) by 0.25 to $0.3 \mathrm{PW}$. The Atlantic OHT almost perfectly compensates the stadial and interstadial changes in total AHT (Figs. 8c, d), demonstrating the role of Bjerknes compensation in the climate system (Bjerknes 1964; Yang et al. 2015b), and is clearly operating efficiently on the millennial time scale.
It is also important here to further elaborate on how these changes in AHT and OHT impact the slow-timescale physics of the D-O oscillation. During the interstadial when the OHT is strong, the AMOC is transporting relatively warm and saline waters to the Irminger basin where the majority of the NADW formation is occurring (Fig. 7). This results in enhanced air-sea heat flux and a reduced meridional temperature gradient of the atmosphere as well as enhanced SSTs (van der Swaluw et al. 2007). With the interstadial AHT being anomalously weak at this stage, the reduced meridional eddy sensible AHT between $40^{\circ}$ to $60^{\circ} \mathrm{N}$ latitude (Fig. $8 \mathrm{~d}$ ) is expected to help facilitate sea ice formation in the high-latitude North Atlantic. As the interstadial initially collapses toward full stadial conditions, sea ice intrusion into the high-latitude North Atlantic is facilitated by the action of southward sea ice transports (Fig. 5). As the stadial conditions begin to become fully established in the North Atlantic, the OHT and air-sea heat flux decrease and the AHT increases (Fig. 8d) resulting in more sensible atmospheric eddy heat transport to higher latitudes. This increased sensible AHT, which has a maximum in midlatitudes, inhibits the southward migration of paleocrystic sea ice that is transported from the Arctic basin into the North Atlantic midlatitudes. Therefore, the reduced interstadial AHT appears to act as a positive feedback that facilitates the southerly advance of sea ice. During the stadial, the enhanced AHT in combination with warm midlatitude North Atlantic SSTs acts as a negative feedback and inhibits the further southerly advance of the sea ice when OHT is severely reduced.

The net surface freshwater flux entering the surface area of an ocean basin is balanced by the freshwater transport across a zonal section in the Atlantic (Wijffels et al. 1992; Talley 2008; Valdivieso et al. 2014). Under modern climate conditions, this includes a transport entering the Arctic and Atlantic through Bering Strait. In this study of the glacial freshwater balance during the Dansgaard-Oeschger oscillation, Bering Strait is closed. The relative contributions of the freshwater transports of the gyre circulation and overturning circulation will not be considered individually, rather only the total freshwater transport will be addressed. In addition to this, the North Atlantic and Arctic basins have storage terms that affect the freshwater budget through the D-O cycle. Using the virtual salt flux formulation (e.g., see Yin et al. 2010) in the POP ocean model, the freshwater budget (Fig. 8) of the glacial Atlantic and Arctic basins (in Sv of freshwater) is expressed as follows: 


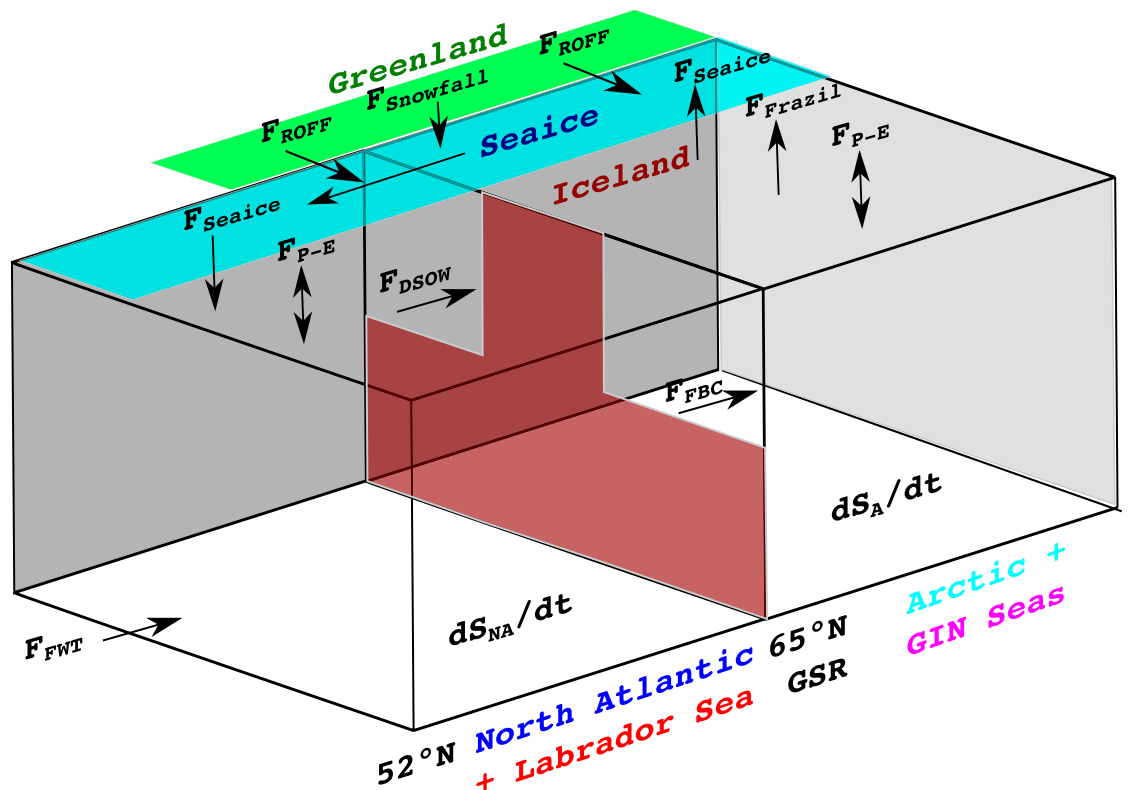

FIG. 9. An idealized two box schematic representation of the glacial North Atlantic and Labrador Sea attached via the GSR to the Arctic and GIN Seas. $F_{\text {Seaice }}$ is the flux of sea ice into or out of each of the boxes. $F_{\text {Frazil }}$ is the frazil ice growth in the ocean. $F_{P-E}$ is the freshwater flux associated with precipitation and evaporation. $F_{\mathrm{ROFF}}$ is the freshwater runoff from the land model. $F_{\mathrm{FWT}}$ is the meridional freshwater transport into the high-latitude basins. $F_{\mathrm{DSO}}$ is the freshwater transport by Denmark Strait overflow water. $F_{\mathrm{FBC}}$ is the freshwater transport by the Faroe Bank Channel overflow water. The sources and sinks of salinity in the basis are $d S_{\mathrm{NA}} / d t$ and $d S_{A} / d t$ for the North Atlantic/Labrador Sea and Arctic/ GIN Seas, respectively.

$$
\begin{aligned}
& \oiint\left(P-E+R+I_{M}+\frac{I_{B}}{S_{0}}+I_{F}\right) \\
& d A_{B}=\oiint \rho v\left(1-\frac{S}{S_{0}}\right) d A_{c}+\frac{1}{S_{0}} \oiiint \rho \frac{d S_{B}}{d t} d V_{B} .
\end{aligned}
$$

The net surface freshwater flux on the left-hand side of Eq. (4) is integrated over the closed area of the entire basin $\left[A_{B}(x, y)\right]$, which in the following analysis is the area of the Arctic Ocean, GIN Seas, Labrador Sea, and North Atlantic basin in the latitude range above $52^{\circ} \mathrm{N}$. On the left-hand side of Eq. (4), the closed area integral is the sum of the precipitation minus evaporation $(P-E)$ plus runoff $R$, as well as the sea ice melt/growth $I_{M}$, brine rejection/accumulation $I_{B}$, and the formation of frazil ice $I_{F}$, which occurs within the ocean model. The units of the surface freshwater fluxes are in $\mathrm{kg} \mathrm{m}^{-2} \mathrm{~s}^{-1}$. The first integral on the right-hand side of Eq. (4) is the freshwater transport through the zonal section $\left[A_{C}(x, z)\right]$ spanning the North Atlantic and Labrador Sea at $52^{\circ} \mathrm{N}$ [Eq. (1)]. The second integral on the right-hand side of Eq. (4) is the rate of change of freshwater storage in the basin expressed as the integral of the rate of change in the mass of salt $S_{B}$ integrated over the volume of all the basins north of $52^{\circ} \mathrm{N}\left[V_{B}(x, y, z)\right]$. The reference salinity
$\left(S_{0}=36.0 \mathrm{psu}\right)$ used in this freshwater budget analysis is approximately the volume averaged salinity of the basins north of $52^{\circ} \mathrm{N}$ over the $\mathrm{D}-\mathrm{O}$ cycle. Note that the melt or growth of sea ice requires that salt be added to or removed from the ocean because sea ice in the coupled model has a base salinity of 4 psu.

The total basin freshwater budget of the high-latitude North Atlantic and Arctic in the coupled model through a D-O cycle is illustrated schematically in the box diagram in Fig. 9. The time series of net surface freshwater flux into the ocean (Fig. 10a) includes the atmosphere and land surface flux as well as the flux of freshwater from the cryosphere. During the stadial period leading up to the D-O warming event there is a net removal of freshwater from the ocean within the four northern high-latitude basins of approximately $0.1 \mathrm{~Sv}$. This freshwater removal is mainly associated with the formation of massive amounts of sea ice $(0.23 \mathrm{~Sv})$, which is subsequently transported out of the high-latitude basins (Fig. 10b). This freshwater removal is partially compensated by runoff and $P-E$ during the stadial of approximately $0.13 \mathrm{~Sv}$. The net flux is balanced by the transport of freshwater northward to compensate for this net removal of freshwater from the high-latitude 

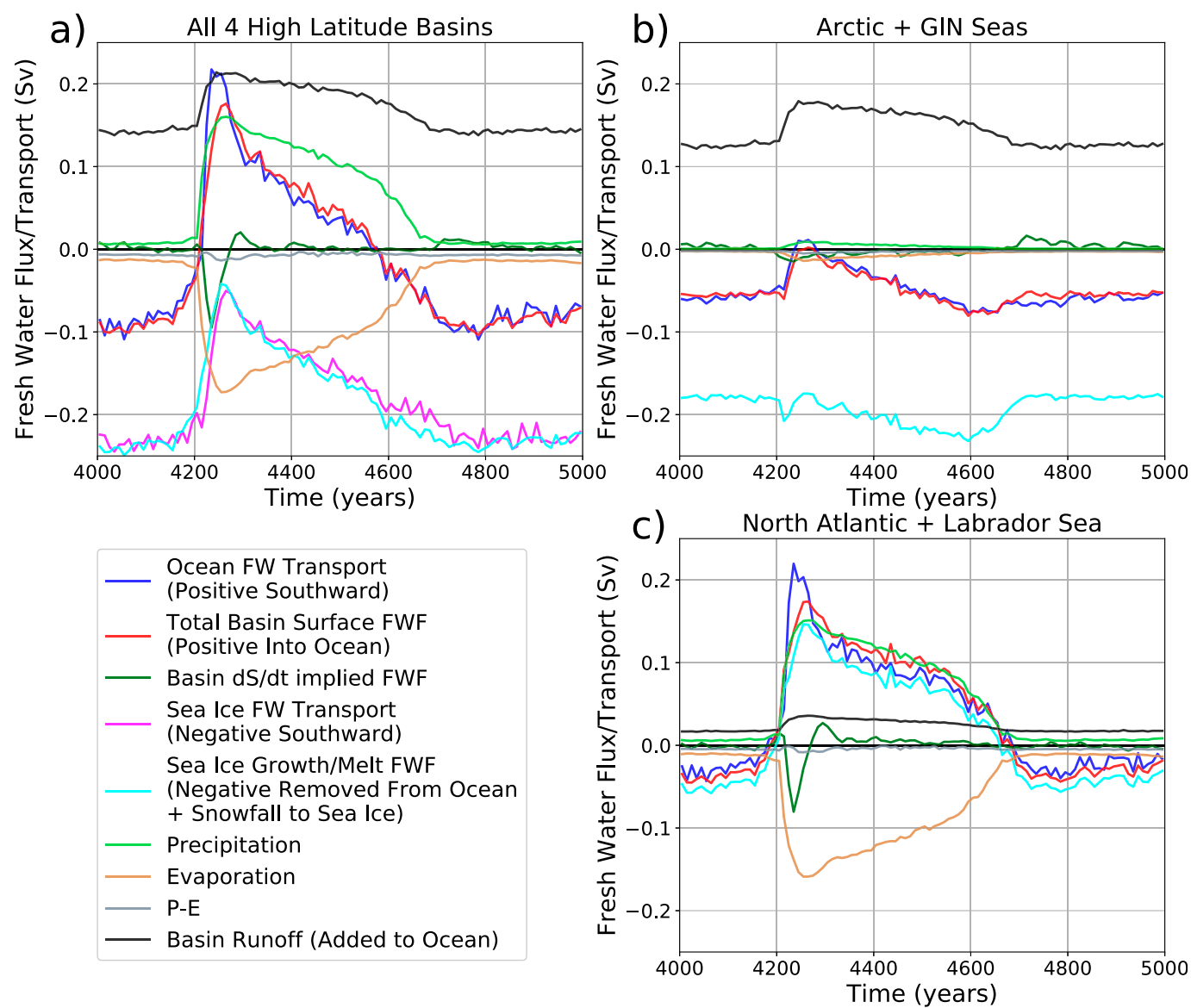

FIG. 10. (a) North Atlantic freshwater transport across the $52^{\circ} \mathrm{N}$ boundary (blue) is balanced by the net surface freshwater flux entering or leaving the high-latitude basins (red), with a small sink or source residual due to a freshening or salinification of the basins (dark green). The net surface freshwater flux is decomposed into the components due to precipitation (light green), evaporation (gold), $P-E$ (gray), runoff (black), and the sea ice growth or melt (cyan). The sea ice freshwater transport southward across the $52^{\circ} \mathrm{N}$ boundary (magenta) nearly balances the freshwater removed from the surface due to the formation of sea ice (cyan). The conversion of snowfall accumulation over sea ice is included in the sea ice growth calculation. (b) As in (a), but for the high-latitude Arctic and GIN Seas basins and (c) lower-latitude North Atlantic $\left(>52^{\circ} \mathrm{N}\right)$ and Labrador Sea basins.

ocean basin. During the interstadial, there is a switch to a net addition of freshwater flux into the high-latitude basins associated with reduced sea ice growth and increased river runoff. This results in a net switch from northward to southward transport of freshwater (or conversely salt transport from south to north) across the zonal section at $52^{\circ} \mathrm{N}$ for approximately 400 years (Fig. 10a). During the middle of the interstadial there is a considerable amount of interstadial freshwater $(0.1 \mathrm{~Sv})$ being exported southward by the ocean across the domain boundary at $52^{\circ} \mathrm{N}$. During this period, the southward transport of freshwater is slightly less than the net flux of freshwater being added to the domain north of the boundary. However, the excess of the surface freshening over the southward transport slowly diminishes as the interstadial progresses. During the final phase of the interstadial-stadial transition, sea ice growth exceeds the amount of sea ice transported out of the high-latitude basins resulting in the final rapid increase in sea ice area and slightly more rapid diminution of the strength of the AMOC (Fig. 9b).

The total freshwater budget of the four high-latitude Arctic and North Atlantic basins (Fig. 9) has been further investigated by measuring the freshwater transports and fluxes occurring in the Arctic and GIN Seas separately from the Labrador Sea and the North Atlantic at latitudes higher than $52^{\circ} \mathrm{N}$. This analysis is designed to illustrate the differences associated with the majority of the sea ice formation regions (Arctic) compared with the regions where the major thermohaline convective activity occurs in the model that is responsible for the D-O warming event (North Atlantic). The Arctic and GIN 
Seas produce a constant volume of sea ice throughout the stadial of approximately $0.2 \mathrm{~Sv}$ (Fig. 10b). During the stadial, there is approximately $0.11 \mathrm{~Sv}$ of $P-E+R$, of which approximately $0.1 \mathrm{~Sv}$ is runoff. This runoff is approximately the same as is characteristic of the modern Arctic basin (Aagaard and Carmack 1989). Thus, the net freshwater removal from the ocean in these highlatitude basins is approximately $0.05 \mathrm{~Sv}$ during the stadial. During the entire D-O cycle, there is a net implied transport of freshwater northward across the Greenland-Scotland Ridge (Fig. 10b), which decreases to near zero just after the D-O warming event. Much of the sea ice that contributes to this net removal of freshwater is transported out of these high-latitude basins into the high-latitude North Atlantic. During the stadial in the high-latitude North Atlantic (Fig. 10c), there is some sea ice formation occurring $(\sim 0.05 \mathrm{~Sv})$, but this is approximately a quarter of the amount occurring in the basins north of the Arctic Circle. Therefore, the Arctic and GIN Seas are playing the role of glacial sea ice factories for paleocrystic sea ice throughout the D-O cycle. The net freshwater sources and sinks implied by the rate of change of volume-averaged salinity in the Arctic and GIN Seas (Fig. 4b) is rather modest (Fig. 10c) but does result in a change of approximately 0.1 to 0.2 psu of salinity through the D-O cycle in these basins. The contributions from runoff and P-E are rather small in the Labrador and high-latitude North Atlantic basins during the $\mathrm{D}-\mathrm{O}$ cycle and do not significantly influence the slow-time-scale dynamics (Fig. 10c). However, the runoff into the Arctic basin and GIN Seas is large (Fig. 10b) and its influence on sea ice growth requires some final discussion.

Modern climate Arctic river runoff is important for setting the stratification in the Arctic basin. An enhanced hydrological cycle under future greenhouse gas forcing will play an important role in Arctic climate as runoff increases into the Arctic basin. The influence of enhanced runoff is expected to increase Arctic stratification resulting in a warmer subsurface and a direct impact on future Arctic sea ice extent (e.g., Nummelin et al. 2016). It is important to address the role of runoff and its impact on the slow-time-scale accumulation of interstadial paleocrystic sea ice in the Arctic basin. The somewhat rudimentary river transport model employed in CCSM4 is inadequate in describing ice stream runoff over the Laurentide and Fennoscandian ice sheets. However, the runoff over the ice sheets would be expected to be small in comparison to the land areas that are not covered by land ice sheets. In this simulation, the Mackenzie River basin is the main outflow source for freshwater runoff in the Canadian Arctic. Within the Siberian River basins, the dominant freshwater outflow occurs from west to east mainly through the $\mathrm{Ob}$, Yenisei, and Lena Rivers, respectively. These river basins are to the east of the Fennoscandian ice sheet and deliver a significant amount of runoff into the Arctic during the summer season in this glacial simulation (Fig. 11). In fact, the Siberian river runoff dominates to a large extent the runoff into the Arctic basin in both the early interstadial (Fig. 11a) and late interstadial periods (Fig. 11c). During the early interstadial, Arctic sea ice growth occurs mainly in July and August and is directly correlated to increasing rates of river runoff at this time (Fig. 11b). It is interesting to note that the Arctic rate of sea ice growth does not continue to extend significantly into the fall and winter seasons during the early interstadial. During the late interstadial, the annual average rate of sea ice growth accelerates (Fig. 4e); however, during this period sea ice growth now occurs from summer to winter. During the interstadial-stadial transition period, the largest growth rate still occurs during the summer season with melt occurring mainly during the spring season. Increasing stratification, freshening of the ocean surface, and the increase in the freezing point of seawater as a result of summer runoff are all expected to play a role in the summer sea ice growth but will not be investigated in further detail here. Rather, it suffices to conclude that Siberian river runoff is an important component in the slow-time-scale physics of the transition from stadial to interstadial and to the outflow of paleocrystic sea ice into regions of winter NADW production.

In summary of our analyses of the slow physics of the $\mathrm{D}-\mathrm{O}$ oscillation cycle, each interstadial is driven to exhaustion on a long time scale by increasing sea ice export from the Arctic basin into the critical NADW formation regions. The resulting net surface freshwater flux results in the creation of a strong halocline beneath an extensive sea ice lid that acts so as to progressively inhibit NADW production following the peak of interstadial conditions. The salinification of the Arctic Ocean following peak interstadial conditions continues with strong brine rejection occurring until the transition to full stadial conditions is established. As the stadial progresses, the net removal of freshwater from the highlatitude basins due to sea ice export and the salinification of the high-latitude North Atlantic basin begins to reinitiate some NADW production, but the actual thermohaline instability that causes the abrupt transition to the interstadial has remained somewhat enigmatic insofar as its ultimate cause is concerned (VP16). Our goal in the next subsection is to understand, given the background information concerning the sea ice controlled high-latitude water cycle, what it is that enables this instability to be realized. 
a)
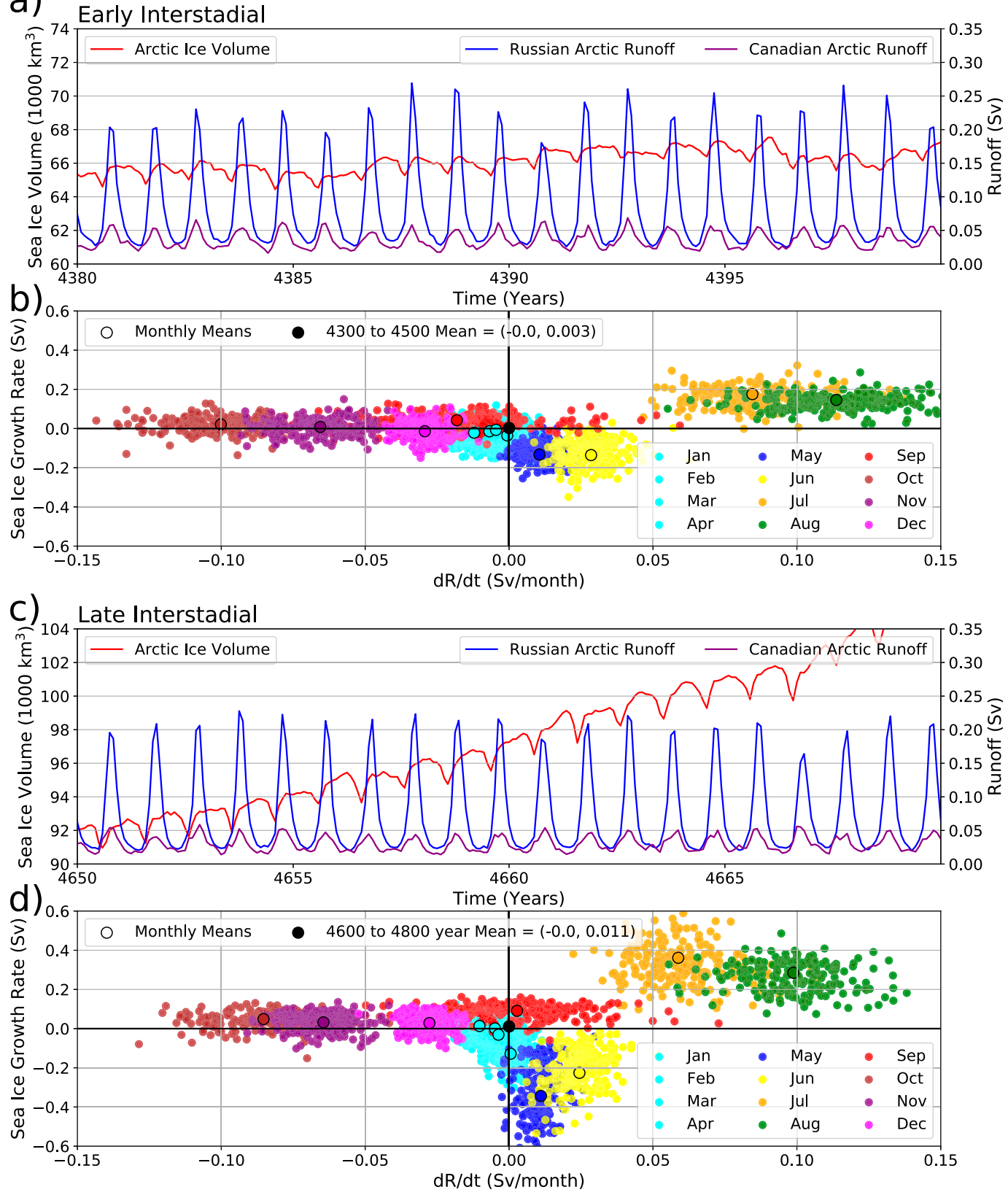

FIG. 11. (a) Early interstadial Arctic sea ice volume and river runoff. The runoff is separated into the components from the river outflow in the Russian Arctic sector and in the Canadian Arctic sector. (b) A scatterplot of the rate of change in total Arctic basin runoff vs the Arctic sea ice growth rate. The monthly mean runoff vs monthly mean sea ice growth rate (open circles) and annual mean runoff vs annual mean growth rate is also shown (solid black circle). (c),(d) As in (a) and (b), but for late interstadial conditions.

\section{d. Fast-time-scale dynamics}

Key to the further investigation of the fast physics instability of the D-O oscillation is the detailed evolution of the salinity distribution in both the surface mixed layer of the high-latitude halocline and in the region below the sharp pycnocline. This transition region forms the lower boundary of the cold and fresh layer that is situated immediately below the stadial sea ice lid. As was demonstrated in VP16, the region of initial instability for the D-O warming event occurs in the IB downstream of the DS sill during a single winter season in the model we are employing. In VP16, a decreasing trend in sea ice thickness was observed to occur in this 


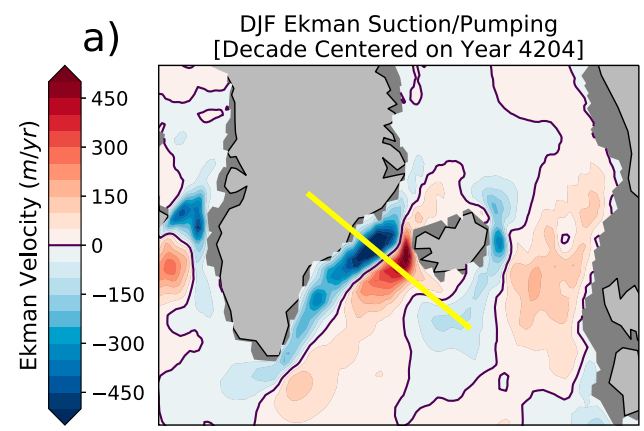

b)

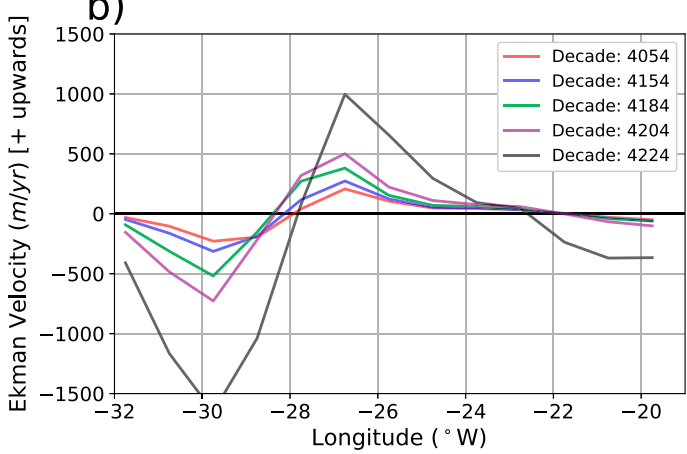

C)

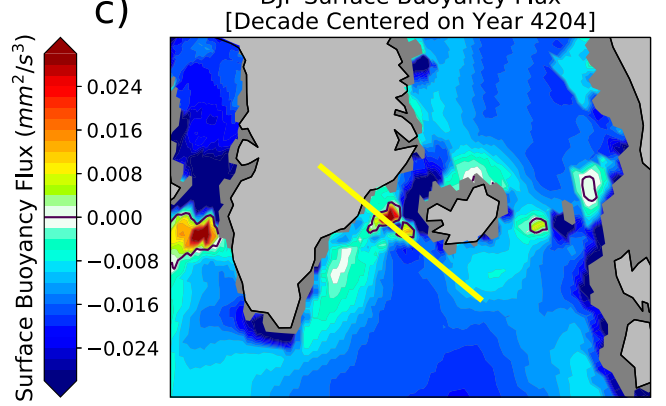

d)

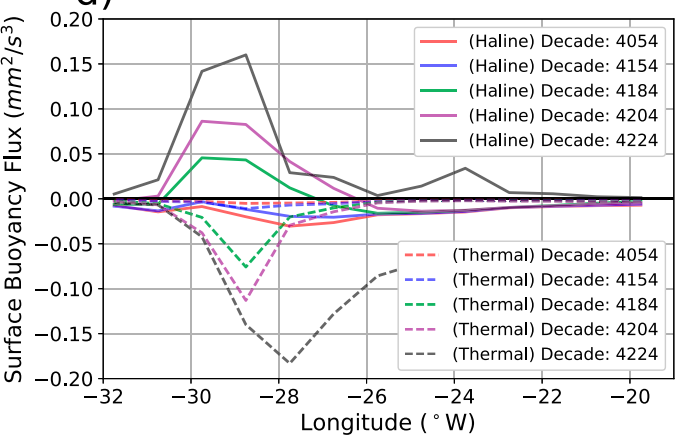

FIG. 12. The decadally averaged winter (DJF) (a) wind stress-induced vertical Ekman velocity in the decade just prior to the D-O warming instability (at year 4212). The decadal average is centered on 31 December of the fourth year of each decade (e.g., 31 Dec 4204). (b) The temporal evolution of the Ekman velocity for a cross section of the East Greenland Current indicated by the yellow line in (a). (c) The decadally averaged DJF total surface buoyancy flux in the decade just prior to the D-O warming instability. (d) The temporal evolution of the surface buoyancy fluxes separated into thermal and haline components for the same transect in (c).

region as the D-O warming transition was approached. However, the role of the haline surface buoyancy flux on the stability of the water column remained unclear.

In the further development of our understanding of the fast physics underlying the stadial-to-interstadial transition, it might be imagined that a mechanism associated with atmospheric mechanical and buoyancy forcing acting on the sea ice lid from above could be important in the fast transition process. Time series of the changes in wind stress forcing and surface buoyancy flux acting across the EGC, south of DS, in the 150 years prior to the D-O warming event are shown in Fig. 12. The along-shelf component of the winter (DJF) wind stress induces a cross-shelf circulation that results from the convergence and divergence of Ekman suction and pumping (Fig. 12a). While the impact of wind stress forcing on the modern observed variability of the EGC remains unclear in detail, initial studies have indicated that the strength of the EGC transport is proportional to the wind stress (e.g., Bacon et al. 2014). In winter, the simulated downwelling along the coast would also act to induce a cross-shelf isopycnal tilt. During much of the stadial, the wind stress forcing remains constant except in the last 50 years prior to the D-O warming instability
(Fig. 12b). The along-shelf wind stress increases the sea ice and mass transport through DS just prior to the transition, but the stratification in the area remains dominated by the strong halocline gradient (see below). As the period of instability is approached (at year 4212) in the simulation of this particular D-O cycle, the region directly downstream of the DS sill begins to freshen somewhat in response to an increase in the net surface freshwater flux (not shown). Deconstructing the winter surface buoyancy flux (Fig. 12c) into its respective haline and thermal buoyancy components demonstrates that the two components are acting in opposition to one another (Fig. 12d). The haline buoyancy flux is dominated by the freshwater flux at the surface, which is mainly due to increasing sea ice melt as the transition is approached. The positive haline component of the buoyancy flux is slightly stronger than the negative thermal buoyancy flux, which is associated with increasing sensible heat loss from below the sea ice lid. We are therefore led to conclude that the surface mechanical and buoyancy forcing are not contributing significantly to the mechanism responsible for the rapid transition from cold stadial to warm interstadial conditions. 
a) DJF at Year 4054
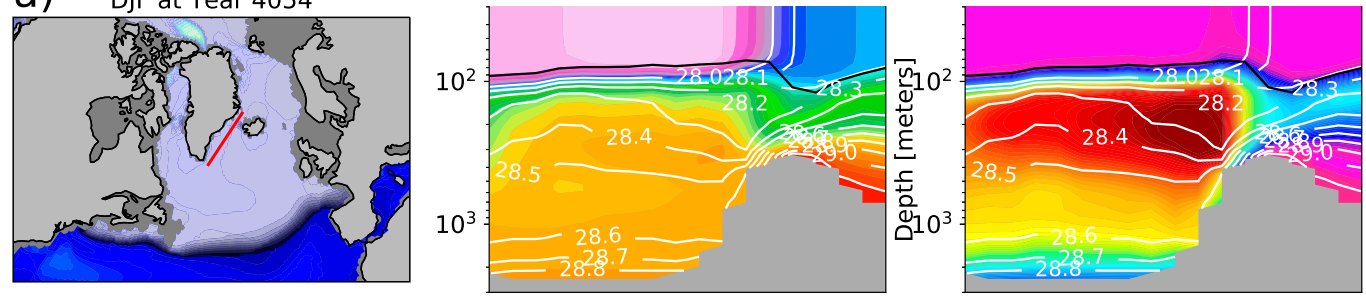

b)
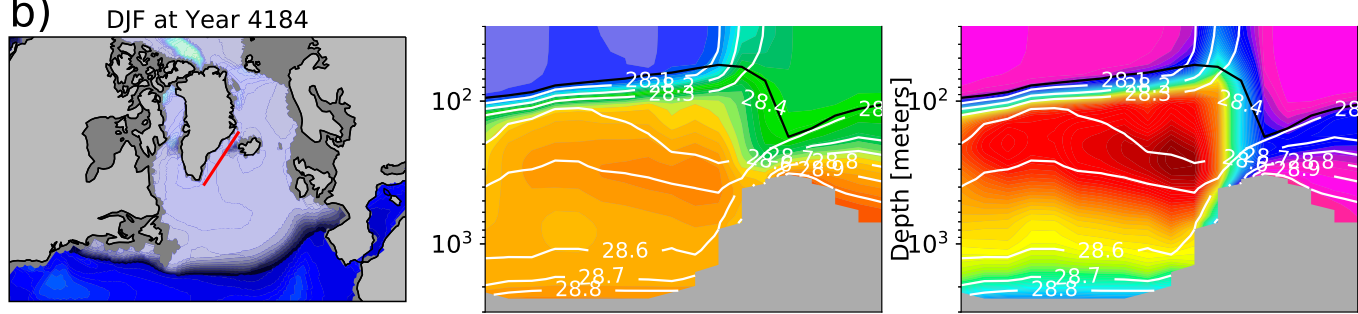

C) DJF at Year 4204
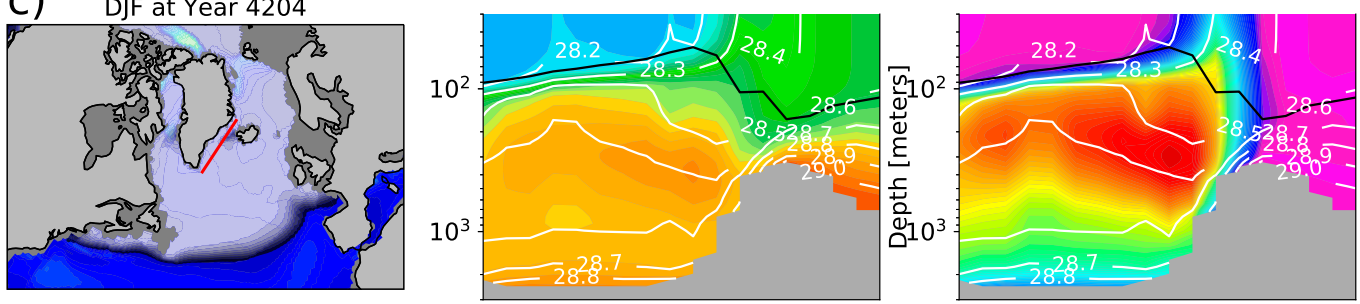

d)

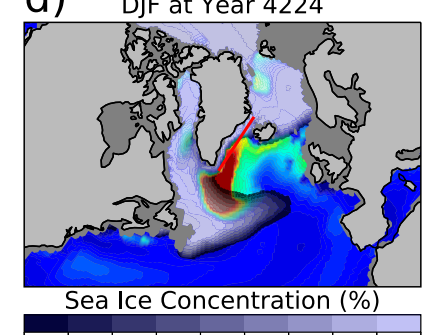

102030405060708090100

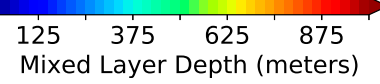

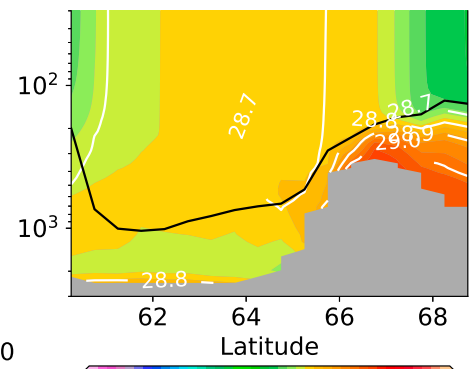

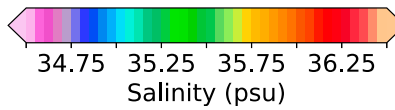

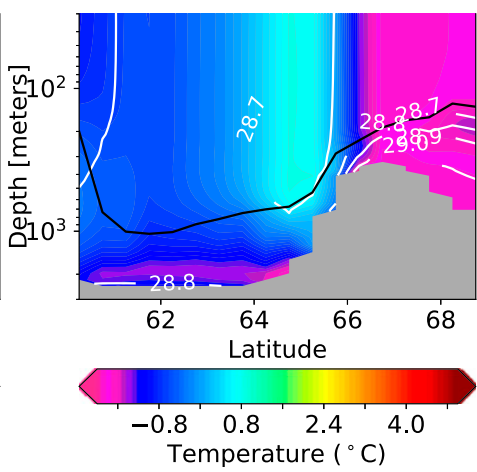

FIG. 13. As in Fig. 7, but for a hydrographic section of salinity and temperature that runs along the East Greenland Current (the red transect in the left panels). The fast evolution of the sea ice concentration, salinity, and temperature are shown for decadal averages (a) 160, (b) 30, and (c) 10 years before the D-O warming transition and (d) 10 years after the D-O warming transition. Potential density anomaly isopycnals are displayed in white contours and the mixed layer depth contour is displayed in black. The vertical axis is on a log scale running from 30 to $2500 \mathrm{~m}$.

To correctly attribute this transition to a specific mechanism, we show in Fig. 13 a transect of ocean hydrography running parallel to the EGC for temperature, salinity, potential density, and mixed layer depth. This ocean transect is indicated by the red line over the sea ice concentration in Fig. 13. What is immediately apparent is the increasing surface salinity in the mixed layer region of the halocline from the surface to approximately $100-\mathrm{m}$ depth. Within the span of 150 years prior to the D-O warming event, the surface mixed layer salinity increases by $0.5 \mathrm{psu}$, while that of the layer below the pycnocline at $100 \mathrm{~m}$ is freshening only slightly. The temperature in the subsurface layer below the pycnocline also begins to cool slightly by approximately $1^{\circ} \mathrm{C}$ over the same period. However, this amounts to a rather modest change to the internal energy of the reservoir that is tapped to drive the convective instability of the sub-sea ice water column that marks the onset of the stadial to interstadial transition. Overall, the trend is therefore toward a reduction in the vertical gradient of 
salinity and a reduction in the stratification across the sharp pycnocline (illustrated by the closely spaced isopycnals). The mixed layer depth, which is a proxy for convective activity, initially begins to rapidly increase just downstream of the sill and results in complete mixing well downstream of the sill in the IB where the polynya forms along with the rapid resumption of deep water production (VP16).

Of interest in the analysis of the onset of convective instability beneath the sea ice lid is the region of unstratified fluid immediately downstream of the sill below the strongly stratified pycnocline (Fig. $13: 66^{\circ} \mathrm{N}, 200-$ to $300-\mathrm{m}$ depth). The flow over the sill has the structure of a density current, which acts as a source of noise that disturbs the stratification in this region and which, in the model, provides the explanation of why the convective instability is first released in close proximity to the sill. The density current itself is not expected to be well resolved in this hydrostatic low-resolution $z$-level ocean model compared to the observations that have been made under modern conditions of the overflow regions of the DS and Faroe Bank channel (Käse et al. 2003; Girton et al.2006). One of the main characteristics of the hydrostatic model concerns the convective adjustment parameterization that is employed to rapidly diffuse mass and momentum in regions of unstable stratification. This may result in excessive entrainment into the density current overflow (Käse and Oschlies 2000). The overflow parameterization in the POP2 ocean model component (Yeager and Danabasoglu 2012) that is employed to at least partially alleviate some of these shortcomings has been turned off in the D-O simulation because this parameterization was tuned to modern bathymetric conditions and is therefore inappropriate for the ice age application. Nevertheless, the noisy lee of the sill is acting to disturb the stratification as the vertical salinity gradient decreases and the onset of the convective instability is approached. This is demonstrated clearly in the supplementary video that is included with this paper. The animation of a latitudinal hydrographic transect in the IB illustrates intense activity downstream of the DS and into the IB region during the winter season in which the initial instability occurs.

It is established in Fig. 13 that the increase in salinity in the polar halocline surface mixed layer is the main mechanism that preconditions the IB to allow the convective instability to onset at the $\mathrm{D}-\mathrm{O}$ warming transition. However, the origin of the changes in the vertical salinity gradient of the critical region where this convective instability occurs remains to be identified. The spatial and temporal evolution of the vertical salinity gradient between 50 and $150 \mathrm{~m}$ in the high-latitude region of the North Atlantic and Arctic is illustrated in

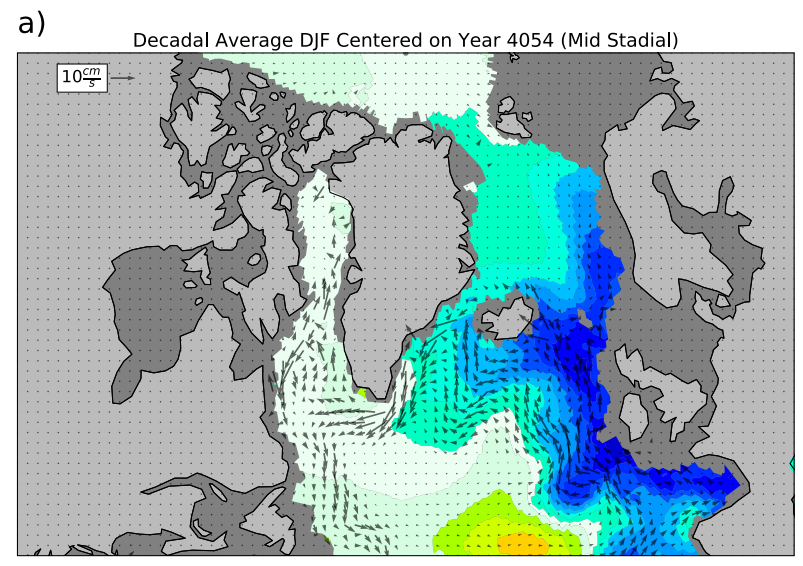

b)

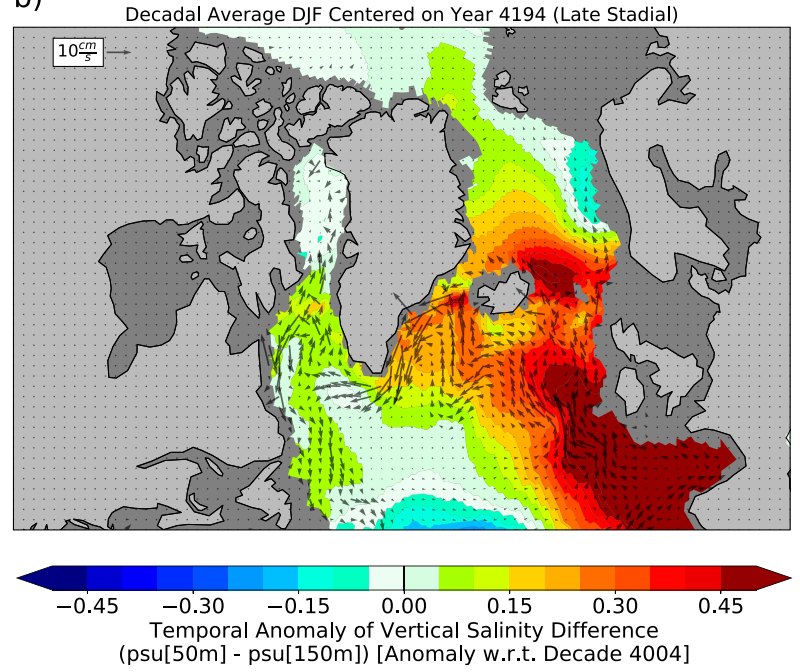

FIG. 14. The evolution of the winter (DJF) decadal average vertical salinity gradient as measured by the difference between the salinity at $50 \mathrm{~m}$ and the salinity at $150 \mathrm{~m}$ (fresher ocean water over saltier ocean water). The halocline gradient is displayed as an anomaly from the decadal average gradient centered on year 4004 at the beginning of the analysis period (gray region in Fig. 1c). Negative values during the (a) midstadial indicated that the surface at $50 \mathrm{~m}$ has freshened compared with the salinity in the layer at $150 \mathrm{~m}$ (relative to the start of the analysis period 50 years prior). The positive values during the (b) late stadial indicate that the mixed layer at $50 \mathrm{~m}$ has increased in salinity compared with the layer at $150 \mathrm{~m}$ (relative to the start of the analysis period). The black vectors denote the average velocity $\left(\mathrm{cm} \mathrm{s}^{-1}\right)$ of the surface circulation in the 0 to $100 \mathrm{~m}$ layer.

Fig. 14. This figure displays the temporally evolving variation of the salinity gradient as it develops over the 200 -yr period prior to the $\mathrm{D}-\mathrm{O}$ warming transition. Of note is the initial increase in the vertical salinity gradient as peak stadial conditions are achieved at year 4050 (Fig. 14a). Subsequent to this, the surface mixed layer begins to become more saline relative to the lower layer toward the end of the stadial period (Fig. 14b). 
Especially apparent is the fact that the evolution of the surface anomalies is controlled by the North Atlantic Current and one of its branches, the Irminger Current. These currents are clearly visible in the velocity vectors averaged over the top $100 \mathrm{~m}$ of the surface ocean (Fig. 14). Therefore, the increases in the subtropical gyre thermocline salinity that accumulates during the stadial appears to be a critical contributor to the fast-time-scale component of the D-O salt oscillator by leading eventually to the salinification of the sub-sea ice halocline as previously discussed in PV14. During cold stadial conditions, the water column below the sea ice is stabilized by the doubly diffusive configuration in which cold freshwater overlies warm salty water. The vertical salinity gradient throughout the stadial is initially sufficient to stabilize the temperature gradient so as to prevent convective instability from occurring. As the salinity of the mixed layer halocline water increases, this stabilization tendency is eliminated and the fast stadialto-interstadial transition occurs, driven by the vertical flux of heat into the base of the sea ice, which is responsible for opening the massive sensible heat polynya discussed in VP16.

For the purpose of constructing our final Fig. 15, a control volume has been selected to enable us to provide a measure of the transport of salt into this region across DS (the Kögur transect; Våge et al. 2013) and the transport of salt that is occurring into the IB by the northern branch of the subpolar gyre (Fig. 15a). This evolution of the mean volume average salinity in the control volume is much the same as in Fig. $4 b$ for the entire North Atlantic section that spans the latitude north of $52^{\circ} \mathrm{N}$ (Fig. 15b). The surface salinity in the top $100 \mathrm{~m}$ of the control volume is changing much more rapidly than the layers below as the D-O warming instability is approached (Fig. 15b). The total salt transport through the DS and that exiting the IB is almost the same (Figs. 15c,d). There is a southward transport of salt across the DS at all levels (Fig. 15c), but the net salt transport through the southern section of the control volume in the IB (Fig. 15d) has a northward component that is much stronger in the mixed layer $(0$ to $100 \mathrm{~m})$ relative to the subpycnocline layer (100 to $200 \mathrm{~m})$. At depth, the salt transport carried by the Deep Western Boundary Current (DWBC) is southward and balances the transport of salt through the DS. In the surface layer ( 0 to $100 \mathrm{~m}$ ) leading up to the transition, the convergence of salt transport exceeds the downward transport of salt at the 100-m level of the control volume (Fig. 15e). This is consistent with the evolution of the salinity changes from the surface to $100-\mathrm{m}$ depth (Fig. 15b). During the stadial, leading up to the D-O warming transition there is an excess of sea ice transport out of the region over that which is entering the control volume through the DS, the result of sea ice growth and brine rejection (Fig. 15f). This salinity flux is also a contributing factor to the increase in the volumeaveraged salinity of the control volume. However, this salinity flux switches to a net input of freshwater a few decades prior to the $\mathrm{D}-\mathrm{O}$ warming transition and would act to freshen the overall salinity of the control volume. Therefore, we must conclude that the convergence of salt into the IB mixed layer region of the halocline is the key mechanism that leads to the relaxation of the vertical salinity gradient in this critical region.

\section{Conclusions}

The analyses presented in this paper have focused upon the critical role that is played by the coupling between the high-latitude North Atlantic and Arctic basins in supporting the millennium time-scale D-O oscillations that dominated climate system variability during MIS3. The critical mechanisms that embody the slow physics and fast physics of D-O oscillation are captured in a highly accurate fashion in our model and have made it possible for us to expand upon the mechanisms previously discussed in PV14 and VP16. The mechanisms underlying the slow time scale physics of the oscillation that are operating during the long transition from warm interstadial to cold stadial conditions, in combination with the fast-time-scale process that is active during the transition from cold stadial to warm interstadial conditions, produce an oscillation of relaxation oscillation form. The processes determinant of the slow physics of the oscillation are summarized in point form as follows:

- The long time scale, on which the relaxation from peak interstadial conditions back toward the cold "stadial" state of the D-O cycle occurs, is associated with the slow progressive increase of paleocrystic sea ice in high northern latitudes over a period of many centuries. The thick multiyear sea ice that is produced during this period is a consequence of the action of two primary mechanisms: 1) Runoff from rivers in the Siberian sector contribute approximately $80 \%$ of the total runoff into the Arctic, mainly during summer. The maxima in the rate of increasing spring/summer runoff are in phase with the maxima in growth rate of Arctic sea ice, which occurs in summer. 2) The action of intense mechanical ridging of sea ice in the enclosed Arctic basin, which has a reduced ocean area during the glacial due to the fall in global sea level, adds through its action to the overall growth of stadial sea ice volume.

- Throughout the progression of the interstadial, with the Bering Strait closed and the Barents Sea covered 
a)

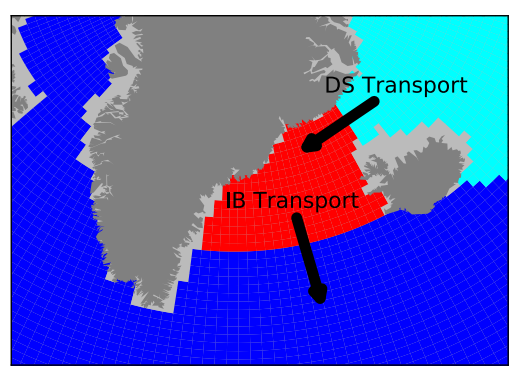

C)

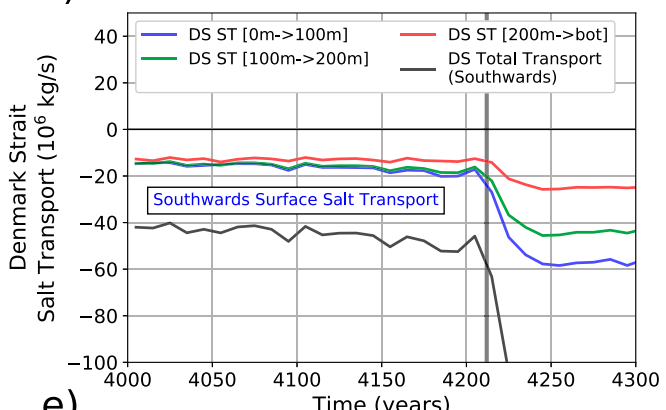

e)

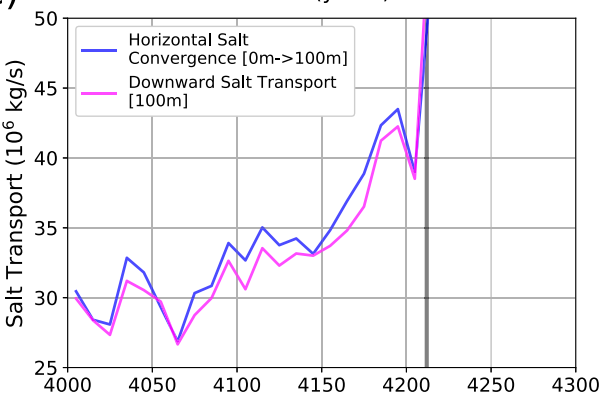

b)
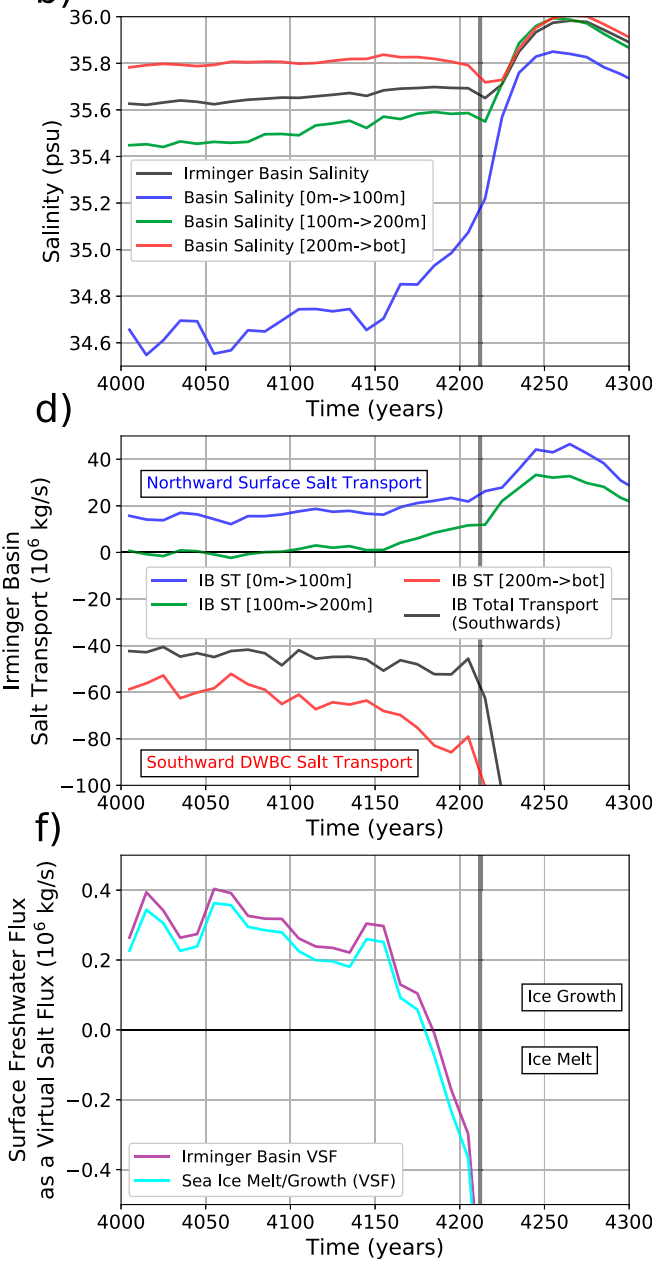

FIG. 15. (a) A control volume (red) employed in the analysis of the salt fluxes into the critical region where the thermohaline instability occurs. Irminger basin transport (IB) and Denmark Strait transport (DS). (b) The evolution of the volume-averaged salinity in the different depth layers of the red basin (blue: 0 to $100 \mathrm{~m}$; green: 100 to $200 \mathrm{~m}$; red: $200 \mathrm{~m}$ to the bottom of the ocean; black: volume average over the total depth). (c) The southward transport (negative values) of salt through Denmark Strait averaged over the same layers as in (a). (d) The northward transport (positive values) across the southern boundary of the control volume. (e) The horizontal convergence of salt transport into the control volume in the surface layer from 0 to $100 \mathrm{~m}$ (blue) is nearly compensated but slightly greater than the downward transport of salt (magenta) through the bottom of the control volume at 100-m depth. (f) The freshwater flux at the surface (purple) is converted here to a virtual salinity flux using a reference salinity of $34.7 \mathrm{psu}$. The virtual salt flux into the ocean attributed to sea ice growth (brine rejection) and melt is shown in cyan. The stadial-interstadial transition is shown by the vertical gray line.

by grounded ice, sea ice is transported through Fram Strait along the EGC into the Labrador Sea and subpolar gyre region of the North Atlantic. In response to sea ice melt in the convectively active Atlantic subpolar gyre, the deep water production in this region decreases as sea ice cover continues to expand over the high-latitude North Atlantic. The restratification of the northernmost Atlantic upper ocean continues, resulting in the extension of the permanent Arctic and GIN Seas halocline over the high-latitude North Atlantic. NADW production in the Atlantic subpolar gyre is then replaced by a reduced AMOC and Glacial North Atlantic Intermediate Water (GNAIW) to the south of the sea ice edge.

- During the initial most active phase of the interstadial, midlatitude Atlantic Ocean heat transport is strong, thereby providing significant air-sea heat flux to the atmosphere at high latitudes, which in turn reduces the meridional near-surface air temperature gradient. Atmospheric heat transport is consequently reduced 
by near-perfect Bjerknes compensation, acting primarily through a reduction in the transient and stationary eddy sensible heat transports. As the interstadial progresses, the meridional atmospheric heat transport gradually increases in parallel with reductions in Atlantic Ocean heat transport and highlatitude air-sea heat flux, the result of reductions in NADW production. This creates a positive feedback, which favors the expansion of the Arctic halocline into the high-latitude North Atlantic. As the stadial state is reestablished, the meridional temperature gradient maximizes and the eddy sensible heat transport increases so as to almost perfectly compensate for the reduced Atlantic Ocean heat transport, limiting further southward sea ice advance.

- In the Arctic basin, the net removal of freshwater from the surface is the result of an imbalance between sea ice formation and runoff. The consequence of this is that there is an excess of polar basin salt export in the two centuries prior to the D-O warming transition.

In addition to the slow-time-scale processes summarized above, the fast physical processes may be similarly summarized as follows.

- The Denmark Strait Overflow (DSO) salt transport and the northeastward surface salt transport by the Irminger Current account for the bulk of the corresponding surface mixed layer salt convergence into the Irminger basin (IB). The result of this transport mainly affects the salinity of the initially cold freshwater layer below the sea ice lid that is bounded below by a sharp pycnocline in the IB downstream of the DSO. Increases in salinity in this surface mixed layer in the final centuries prior to the $\mathrm{D}-\mathrm{O}$ warming transition is instrumental in modifying the halocline buoyancy structure that forms in response to the extreme southward extension of the sea ice lid during the stadial.

- The precise mechanism through which water columns in the IB are initially destabilized at the warming transition appear to be associated with the details of the fluid mechanics of the flow of density stratified fluid over the sill in DS. The stratification in the lee of the sill is ultimately influenced by the noisy flow properties of the density current that flows across the DS sill. The transition is found to occur in the model in a single winter season when stratification through the pycnocline becomes destabilized through the action of a thermohaline convective instability previously described in VP16.

Ongoing work to be discussed elsewhere will assess, using direct numerical simulation methods, the detailed characteristics of the stratified turbulence that actually characterizes the mixing process that operates during the rapid stadial-interstadial transition. Further experiments will also be required to address the observation that, in a Bond cycle (Bond et al. 1993) of D-O oscillations as illustrated in Fig. 1a, successive oscillations have a slightly smaller amplitude and period. Compared with the D-O oscillations of even the most modest amplitude that are observed in the ice core records, the model still has a period that is somewhat short compared with this observed record, an additional issue that remains to be resolved. This has the important implication that the role that various model dependencies play in the simulation of millennial scale glacial climate variability will require further analysis. For example, the suite of simulations that constitute the Coupled Model Intercomparison Project (CMIP) and the Large Ensemble Community Project (LENS) have investigated model dependencies in the simulation of past, present, and future climate states (e.g., Weber et al. 2007; Kwok 2011; Snape and Forster 2014; Kay et al. 2015; Nummelin et al. 2017). The simulation of MIS3 millennial-scale climate variability in response to internal and external forcing factors may provide a unique additional opportunity for model validation. More importantly, model intercomparison studies of glacial climate variability may also be employed to constrain Earth system climate sensitivity in future studies.

Acknowledgments. The research has relied upon computational resources provided by the SciNet facility for high performance computation of the University of Toronto through the Compute Canada resource allocation process. SciNet is a component of the Compute Canada HPC platform that is funded by the Province of Ontario, the Canadian Foundation for Innovation (CFI), and the University of Toronto. The research of W.R.P at Toronto is supported by NSERC Discovery Grant A9627. Data employed in the production of this manuscript and supplementary materials will be provided upon request by the corresponding author of this paper, G. Vettoretti, at g.vettoretti@utoronto.ca.

\section{REFERENCES}

Aagaard, K., and E. C. Carmack, 1989: The role of sea ice and other fresh water in the Arctic circulation. J. Geophys. Res., 94, 14 485-14 498, https://doi.org/10.1029/JC094iC10p14485.

Adkins, J. F., A. P. Ingersoll, and C. Pasquero, 2005: Rapid climate change and conditional instability of the glacial deep ocean from the thermobaric effect and geothermal heating. Quat. Sci. Rev., 24, 581-594, https://doi.org/10.1016/j.quascirev.2004.11.005.

Andersen, K. K., and Coauthors, 2004: High-resolution record of Northern Hemisphere climate extending into the last 
interglacial period. Nature, 431, 147-151, https://doi.org/ 10.1038/nature02805.

Argus, D. F., W. R. Peltier, R. Drummond, and S. Moore, 2014: The Antarctic component of glacial isostatic adjustment model ICE-6G_C (VM5a) based upon GPS measurements of vertical motion of the crust, exposure age dating of ice thickness variations and relative sea level histories. Geophys. J. Int. 198, 537-563, https://doi.org/10.1093/gji/ggu140.

Bacon, S., A. Marshall, N. P. Holliday, Y. Aksenov, and S. R. Dye, 2014: Seasonal variability of the East Greenland coastal current. J. Geophys. Res. Oceans, 119, 3967-3987, https://doi.org/ 10.1002/2013JC009279.

Bassis, J. N., S. V. Petersen, and L. Mac Cathles, 2017: Heinrich events triggered by ocean forcing and modulated by isostatic adjustment. Nature, 542, 332-334, https://doi.org/10.1038/ nature 21069

Bjerknes, J., 1964: Atlantic air-sea interaction. Advances in Geophysics, Vol. 10, Academic Press, 1-82, https://doi.org/10.1016/ S0065-2687(08)60005-9.

Bond, G., W. Broecker, S. Johnsen, J. McManus, L. Labeyrie, J. Jouzel, and G. Bonani, 1993: Correlations between climate records from North Atlantic sediments and Greenland ice. Nature, 365, 143-147, https://doi.org/10.1038/365143a0.

Bourgain, P., and J.-C. Gascard, 2011: The Arctic Ocean halocline and its interannual variability from 1997 to 2008. Deep-Sea Res. I, 58, 745-756, https://doi.org/10.1016/j.dsr.2011.05.001.

Bradley, R. S., and J. H. England, 2008: The Younger Dryas and the sea of ancient ice. Quat. Res., 70, 1-10, https://doi.org/ 10.1016/j.yqres.2008.03.002.

Broecker, W. S., D. M. Peteet, and D. Rind, 1985: Does the oceanatmosphere system have more than one stable mode of operation? Nature, 315, 21-26, https://doi.org/10.1038/315021a0.

_, G. Bond, M. Klas, G. Bonani, and W. Wolfli, 1990: A salt oscillator in the glacial Atlantic? 1. The concept. Paleoceanography, 5, 469-477, https://doi.org/10.1029/PA005i004p00469.

Bryan, K., and L. J. Lewis, 1979: A water mass model of the world ocean. J. Geophys. Res., 84, 2503-2517, https://doi.org/10.1029/ JC084iC05p02503.

Colin de Verdière, A., 2007: A simple model of millennial oscillations of the thermohaline circulation. J. Phys. Oceanogr., 37, 1142-1155, https://doi.org/10.1175/JPO3056.1.

-, M. Ben Jelloul, and F. Sévellec, 2006: Bifurcation structure of thermohaline millennial oscillations. J. Climate, 19, 57775795, https://doi.org/10.1175/JCLI3950.1.

Cronin, T. M., L. Gemery, W. M. Briggs, M. Jakobsson, L. Polyak, and E. M. Brouwers, 2010: Quaternary Sea-ice history in the Arctic Ocean based on a new Ostracode sea-ice proxy. Quat. Sci. Rev., 29, 3415-3429, https://doi.org/10.1016/ j.quascirev.2010.05.024.

Czaja, A., and J. Marshall, 2006: The partitioning of poleward heat transport between the atmosphere and ocean. J. Atmos. Sci. 63, 1498-1511, https://doi.org/10.1175/JAS3695.1.

Danabasoglu, G., W. G. Large, J. J. Tribbia, P. R. Gent, B. P. Briegleb, and J. C. McWilliams, 2006: Diurnal coupling in the tropical oceans of CCSM3. J. Climate, 19, 2347-2365, https://doi.org/10.1175/JCLI3739.1.

Dansgaard, W., and Coauthors, 1993: Evidence for general instability of past climate from a 250-kyr ice-core record. Nature, 364, 218-220, https://doi.org/10.1038/364218a0.

Dokken, T. M., K. H. Nisancioglu, C. Li, D. S. Battisti, and C. Kissel, 2013: Dansgaard-Oeschger cycles: Interactions between ocean and sea ice intrinsic to the Nordic seas. Paleoceanography, 28, 491-502, https://doi.org/10.1002/palo.20042.
Ferrari, R., J. C. McWilliams, V. M. Canuto, and M. Dubovikov, 2008: Parameterization of eddy fluxes near oceanic boundaries. J. Climate, 21, 2770-2789, https://doi.org/10.1175/2007JCLI1510.1.

Gent, P. R., and J. C. McWilliams, 1990: Isopycnal mixing in ocean circulation models. J. Phys. Oceanogr., 20, 150-155, https:// doi.org/10.1175/1520-0485(1990)020<0150:IMIOCM>2.0.CO;2.

— , and Coauthors, 2011: The Community Climate System Model version 4. J. Climate, 24, 4973-4991, https://doi.org/ 10.1175/2011JCLI4083.1.

Girton, J. B., L. J. Pratt, D. A. Sutherland, and J. F. Price, 2006: Is the Faroe Bank Channel overflow hydraulically controlled? J. Phys. Oceanogr., 36, 2340-2349, https://doi.org/10.1175/ JPO2969.1.

Griffiths, S. D., and W. R. Peltier, 2008: Megatides in the Arctic Ocean under glacial conditions. Geophys. Res. Lett., 35, L08605, https://doi.org/10.1029/2008GL033263.

— , and _ 2009: Modeling of polar ocean tides at the Last Glacial Maximum: Amplification, sensitivity, and climatological implications. J. Climate, 22, 2905-2924, https://doi.org/ 10.1175/2008JCLI2540.1.

Henry, L. G., J. F. McManus, W. B. Curry, N. L. Roberts, A. M. Piotrowski, and L. D. Keigwin, 2016: North Atlantic Ocean circulation and abrupt climate change during the last glaciation. Science, 353, 470-474, https://doi.org/10.1126/ science.aaf5529.

Hoff, U., T. L. Rasmussen, R. Stein, M. M. Ezat, and K. Fahl, 2016: Sea ice and millennial-scale climate variability in the Nordic seas $90 \mathrm{kyr}$ ago to present. Nat. Commun., 7, 12247, https:// doi.org/10.1038/ncomms12247.

Huber, C., and Coauthors, 2006: Isotope calibrated Greenland temperature record over Marine Isotope Stage 3 and its relation to $\mathrm{CH}_{4}$. Earth Planet. Sci. Lett., 243, 504-519, https:// doi.org/10.1016/j.epsl.2006.01.002.

Hunke, E. C., and W. H. Lipscomb, 2010: CICE: The Los Alamos Sea Ice model documentation and software user's manual version 4.1. Los Alamos National Laboratory Tech. Rep. LACC-06-012, $76 \mathrm{pp}$

Jahn, A., and Coauthors, 2012: Late-twentieth-century simulation of Arctic sea ice and ocean properties in the CCSM4. J. Climate, 25, 1431-1452, https://doi.org/10.1175/JCLI-D-11-00201.1.

Jayne, S. R., 2009: The impact of abyssal mixing parameterizations in an ocean general circulation model. J. Phys. Oceanogr., 39, 1756-1775, https://doi.org/10.1175/2009JPO4085.1.

Käse, R. H., and A. Oschlies, 2000: Flow through Denmark Strait. J. Geophys. Res., 105, 28 527-28 546, https://doi.org/10.1029/ 2000JC900111.

_ J. B. Girton, and T. B. Sanford, 2003: Structure and variability of the Denmark Strait Overflow: Model and observations. J. Geophys. Res., 108, 3181, https://doi.org/10.1029/ 2002JC001548.

Kay, J. E., and Coauthors, 2015: The Community Earth System Model (CESM) Large Ensemble Project: A community resource for studying climate change in the presence of internal climate variability. Bull. Amer. Meteor. Soc., 96, 1333-1349, https://doi.org/10.1175/BAMS-D-13-00255.1.

Kleppin, H., M. Jochum, B. Otto-Bliesner, C. A. Shields, and S. Yeager, 2015: Stochastic atmospheric forcing as a cause of Greenland climate transitions. J. Climate, 28, 7741-7763, https://doi.org/10.1175/JCLI-D-14-00728.1.

Knies, J., P. Cabedo-Sanz, S. T. Belt, S. Baranwal, S. Fietz, and A. Rosell-Melé, 2014: The emergence of modern sea ice cover in the Arctic Ocean. Nat. Commun., 5, 5608, https://doi.org/ $10.1038 /$ ncomms6608. 
Kwok, R., 2011: Observational assessment of Arctic Ocean sea ice motion, export, and thickness in CMIP3 climate simulations. J. Geophys. Res., 116, C00D05, https://doi.org/10.1029/ 2011JC007004.

Large, W. G., J. C. McWilliams, and S. C. Doney, 1994: Oceanic vertical mixing: A review and a model with a nonlocal boundary layer parameterization. Rev. Geophys., 32, 363-403, https://doi.org/10.1029/94RG01872.

Levine, X. J., and T. Schneider, 2011: Response of the Hadley circulation to climate change in an aquaplanet GCM coupled to a simple representation of ocean heat transport. J. Atmos. Sci., $\mathbf{6 8}$, 769-783, https://doi.org/10.1175/2010JAS3553.1.

Li, C., D. S. Battisti, and C. M. Bitz, 2010: Can North Atlantic sea ice anomalies account for Dansgaard-Oeschger climate signals? J. Climate, 23, 5457-5475, https://doi.org/10.1175/ 2010JCLI3409.1.

Malkus, W. V., 1972: Non-periodic convection at high and low Prandtl number. Mem. Soc. Roy. Sci. Liege, 4, 125-128.

Manurung, A., 2016: IP25 and brassicasterol: The biomarker as ice proxy for the sea ice covering in the Arctic Ocean. J. Teknol., 78, 9-14, https://doi.org/10.11113/jt.v78.8630.

Marshall, J., and F. Schott, 1999: Open-ocean convection: Observations, theory, and models. Rev. Geophys., 37, 1-64, https:// doi.org/10.1029/98RG02739.

Mitsui, T., and M. Crucifix, 2016: Influence of external forcings on abrupt millennial-scale climate changes: a statistical modelling study. Climate Dyn., 48, 2729-2749, https://doi.org/10.1007/ s00382-016-3235-z.

Munk, W. H., 1966: Abyssal recipes. Deep-Sea Res. Oceanogr. Abstr., 13, 707-730, https://doi.org/10.1016/0011-7471(66)90602-4.

Murton, J. B., M. D. Bateman, S. R. Dallimore, J. T. Teller, and Z. Yang, 2010: Identification of Younger Dryas outburst flood path from Lake Agassiz to the Arctic Ocean. Nature, 464, 740 743, https://doi.org/10.1038/nature08954.

Nummelin, A., M. Ilicak, C. Li, and L. H. Smedsrud, 2016: Consequences of future increased Arctic runoff on Arctic Ocean stratification, circulation, and sea ice cover. J. Geophys. Res. Oceans, 121, 617-637, https://doi.org/10.1002/2015JC011156.

— C C. Li, and P. J. Hezel, 2017: Connecting ocean heat transport changes from the midlatitudes to the Arctic Ocean. Geophys. Res. Lett., 44, 1899-1908, https://doi.org/10.1002/ 2016 GL071333.

Peltier, W. R., and R. G. Fairbanks, 2006: Global glacial ice volume and Last Glacial Maximum duration from an extended Barbados sea level record. Quat. Sci. Rev., 25, 3322-3337, https:// doi.org/10.1016/j.quascirev.2006.04.010.

__, and G. Vettoretti, 2014: Dansgaard-Oeschger oscillations predicted in a comprehensive model of glacial climate: A "kicked" salt oscillator in the Atlantic. Geophys. Res. Lett., 41, 7306-7313, https://doi.org/10.1002/2014GL061413.

— D. F. Argus, and R. Drummond, 2015: Space geodesy constrains ice age terminal deglaciation: The global ICE-6G_C (VM5a) model. J. Geophys. Res. Solid Earth, 120, 450-487, https://doi.org/10.1002/2014JB011176.

Rahmstorf, S., 2002: Ocean circulation and climate during the past 120,000 years. Nature, 419, 207-214, https://doi.org/10.1038/ nature 01090.

Rasmussen, T. L., and E. Thomsen, 2004: The role of the North Atlantic Drift in the millennial timescale glacial climate fluctuations. Palaeogeogr. Palaeoclimatol. Palaeoecol., 210, 101116, https://doi.org/10.1016/j.palaeo.2004.04.005.

Rial, J. A., and M. Yang, 2007: Is the frequency of abrupt climate change modulated by the orbital insolation? Ocean Circula- tion: Mechanisms and Impacts_-Past and Future Changes of Meridional Overturning, A. Schmittner, J. C. H. Chiang, and S. R. Hemming, Eds., Amer. Geophys. Union, 167-174.

- , and R. Saha, 2011: Modeling abrupt climate change as the interaction between sea ice extent and mean ocean temperature under orbital insolation forcing. Abrupt Climate Change: Mechanisms, Patterns, and Impacts, H. Rashid, L. Polyak, and E. Mosley-Thompson, Eds., Amer. Geophys. Union, 57-74.

Roberts, A., and R. Saha, 2017: Relaxation oscillations in an idealized ocean circulation model. Climate Dyn., 48, 2123-2134, https://doi.org/10.1007/s00382-016-3195-3.

Saha, R., 2015: Millennial-scale oscillations between sea ice and convective deep water formation. Paleoceanography, 30, 1540-1555, https://doi.org/10.1002/2015PA002809.

Sakai, K., and W. R. Peltier, 1995: A simple model of the Atlantic thermohaline circulation: Internal and forced variability with paleoclimatological implications. J. Geophys. Res., 100, 13455 13 479, https://doi.org/10.1029/95JC00616.

— thermohaline circulation: Paleoceanographic analyses of the origins of ice-age climate variability. J. Geophys. Res., 101, 22 535-22 562, https://doi.org/10.1029/96JC00539.

—, and —, 1997: Dansgaard-Oeschger oscillations in a coupled atmosphere-ocean climate model. J. Climate, 10, 949-970, https://doi.org/10.1175/1520-0442(1997)010<0949: DOOIAC $>2.0 . \mathrm{CO} ; 2$.

— , and - 1999: A dynamical systems model of the Dansgaard-Oeschger oscillation and the origin of the Bond cycle. J. Climate, 12, 2238-2255, https://doi.org/10.1175/15200442(1999)012<2238:ADSMOT>2.0.CO;2.

Sévellec, F., and A. V. Fedorov, 2015: Unstable AMOC during glacial intervals and millennial variability: The role of mean sea ice extent. Earth Planet. Sci. Lett., 429, 60-68, https:// doi.org/10.1016/j.eps1.2015.07.022.

Shaffer, G., S. M. Olsen, and C. J. Bjerrum, 2004: Ocean subsurface warming as a mechanism for coupling Dansgaard-Oeschger climate cycles and ice-rafting events. Geophys. Res. Lett., 31, L24202, https://doi.org/10.1029/2004GL020968.

Shao, Z.-G., and P. D. Ditlevsen, 2016: Contrasting scaling properties of interglacial and glacial climates. Nat. Commun., 7 , 10951, https://doi.org/10.1038/ncomms10951.

Singh, H. A., D. S. Battisti, and C. M. Bitz, 2014: A heuristic model of Dansgaard-Oeschger cycles. Part I: Description, results, and sensitivity studies. J. Climate, 27, 4337-4358, https://doi.org/ 10.1175/JCLI-D-12-00672.1.

Smith, R., and Coauthors, 2010: The Parallel Ocean Program (POP) reference manual: Ocean component of the Community Climate System Model (CCSM) and Community Earth System Model (CESM). Los Alamos National Laboratory Rep. LAUR-01853, 141 pp.

Snape, T. J., and P. M. Forster, 2014: Decline of Arctic sea ice: Evaluation and weighting of CMIP5 projections. J. Geophys. Res. Atmos., 119, 546-554, https://doi.org/10.1002/2013JD020593.

Stastna, M., and W. R. Peltier, 2007: On box models of the North Atlantic thermohaline circulation: Intrinsic and extrinsic millennial timescale variability in response to deterministic and stochastic forcing. J. Geophys. Res., 112, C10023, https:// doi.org/10.1029/2006JC003938.

Stein, R., and K. Fahl, 2013: Biomarker proxy shows potential for studying the entire Quaternary Arctic sea ice history. Org. Geochem., 55, 98-102, https://oi.org/10.1016/ j.orggeochem.2012.11.005. 
Stommel, H., 1961: Thermohaline convection with two stable regimes of flow. Tellus, 13, 224-230, https://doi.org/10.3402/ tellusa.v13i2.9491.

Su, Z., A. P. Ingersoll, and F. He, 2016: On the abruptness of Bølling-Allerød warming. J. Climate, 29, 4965-4975, https:// doi.org/10.1175/JCLI-D-15-0675.1.

Talley, L. D., 2008: Freshwater transport estimates and the global overturning circulation: Shallow, deep and throughflow components. Prog. Oceanogr., 78, 257-303, https://doi.org/10.1016/ j.pocean.2008.05.001.

Tarasov, L., and W. R. Peltier, 2005: Arctic freshwater forcing of the Younger Dryas cold reversal. Nature, 435, 662-665, https:// doi.org/10.1038/nature03617.

Timmermann, A., H. Gildor, M. Schulz, and E. Tziperman, 2003: Coherent resonant millennial-scale climate oscillations triggered by massive meltwater pulses. J. Climate, 16, 25692585, https://doi.org/10.1175/1520-0442(2003)016<2569: CRMCOT $>2.0 . \mathrm{CO} ; 2$.

Tréguier, A.-M., and Coauthors, 2014: Meridional transport of salt in the global ocean from an eddy-resolving model. Ocean Sci., 10, 243-255, https://doi.org/10.5194/os-10-243-2014.

Våge, K., and Coauthors, 2013: Revised circulation scheme north of the Denmark Strait. Deep-Sea Res. I, 79, 20-39, https:// doi.org/10.1016/j.dsr.2013.05.007.

Valdivieso, M., K. Haines, H. Zuo, and D. Lea, 2014: Freshwater and heat transports from global ocean synthesis. J. Geophys. Res. Oceans, 119, 394-409, https://doi.org/10.1002/ 2013JC009357.

Van der Swaluw, E., S. S. Drijfhout, and W. Hazeleger, 2007: Bjerknes compensation at high northern latitudes: The ocean forcing the atmosphere. J. Climate, 20, 6023-6032, https:// doi.org/10.1175/2007JCLI1562.1.

Vettoretti, G., and W. R. Peltier, 2013: Last Glacial Maximum ice sheet impacts on North Atlantic climate variability: The importance of the sea ice lid. Geophys. Res. Lett., 40, 6378-6383, https://doi.org/10.1002/2013GL058486.

— and _ 2015: Interhemispheric air temperature phase relationships in the nonlinear Dansgaard-Oeschger oscillation. Geophys. Res. Lett., 42, 1180-1189, https://doi.org/10.1002/ 2014GL062898.

—, and — 2016: Thermohaline instability and the formation of glacial North Atlantic super polynyas at the onset of Dansgaard-Oeschger warming events. Geophys. Res. Lett., $\mathbf{4 3}$, 5336-5344, https://doi.org/10.1002/2016GL068891.

Weaver, A. J., and T. M. Hughes, 1994: Rapid interglacial climate fluctuations driven by North Atlantic Ocean circulation. $\mathrm{Na}$ ture, 367, 447-450, https://doi.org/10.1038/367447a0.
Weber, S. L., and Coauthors, 2007: The modern and glacial overturning circulation in the Atlantic Ocean in PMIP coupled model simulations. Climate Past, 3, 51-64, https://doi.org/ 10.5194/cp-3-51-2007.

Welander, P., 1986: Thermohaline effects in the ocean circulation and related simple models. Large-Scale Transport Processes in Oceans and Atmosphere, J. Willebrand and D. Anderson, Eds., Springer, 163-200.

Wijffels, S. E., R. W. Schmitt, H. L. Bryden, and A. Stigebrandt, 1992: Transport of freshwater by the oceans. J. Phys. Oceanogr., 22, 155-162, https://doi.org/10.1175/1520-0485(1992)022<0155: TOFBTO $>2.0 . \mathrm{CO} ; 2$.

Winton, M., and E. S. Sarachik, 1993: Thermohaline oscillations induced by strong steady salinity forcing of ocean general circulation models. J. Phys. Oceanogr., 23, 1389-1410, https://doi.org/10.1175/ 1520-0485(1993)023<1389:TOIBSS $>2.0$. CO; 2 .

Xiao, X., R. Stein, and K. Fahl, 2015: MIS 3 to MIS 1 temporal and LGM spatial variability in Arctic Ocean sea ice cover: Reconstruction from biomarkers. Paleoceanography, 30, 969983, https://doi.org/10.1002/2015PA002814.

Yang, H., Q. Li, K. Wang, Y. Sun, and D. Sun, 2015a: Decomposing the meridional heat transport in the climate system. Climate Dyn., 44, 2751-2768, https://doi.org/10.1007/ s00382-014-2380-5.

—, Y. Zhao, Z. Liu, Q. Li, F. He, and Q. Zhang, 2015b: Heat transport compensation in atmosphere and ocean over the past 22,000 years. Sci. Rep., 5, 16661, https://doi.org/10.1038/ srep16661.

Yeager, S., and G. Danabasoglu, 2012: Sensitivity of Atlantic meridional overturning circulation variability to parameterized Nordic sea overflows in CCSM4. J. Climate, 25, 2077-2103, https://doi.org/10.1175/JCLI-D-11-00149.1.

Yin, J., R. J. Stouffer, M. J. Spelman, and S. M. Griffies, 2010: Evaluating the uncertainty induced by the virtual salt flux assumption in climate simulations and future projections. J. Climate, 23, 80-96, https://doi.org/10.1175/2009JCLI3084.1.

Zhang, X., G. Lohmann, G. Knorr, and C. Purcell, 2014: Abrupt glacial climate shifts controlled by ice sheet changes. Nature, 512, 290-294, https://doi.org/10.1038/nature13592.

G. Knorr, G. Lohmann, and S. Barker, 2017: Abrupt North Atlantic circulation changes in response to gradual $\mathrm{CO}_{2}$ forcing in a glacial climate state. Nat. Geosci., 10, 518-523, https://doi.org/10.1038/ngeo2974.

Zhou, H., and Coauthors, 2014: Heinrich event 4 and Dansgaard/ Oeschger events 5-10 recorded by high-resolution speleothem oxygen isotope data from central China. Quat. Res., 82, 394404, https://doi.org/10.1016/j.yqres.2014.07.006. 